\title{
General Equilibrium Impacts Of a Federal Clean Energy Standard
}

\author{
Lawrence H. Goulder ${ }^{\mathrm{a}}$ b, c \\ Marc A. C. Hafstead ${ }^{\mathrm{b}}$ \\ Roberton C. Williams III ${ }^{\text {b, c, d }}$
}

December 2013

${ }^{\text {a }}$ Stanford University

${ }^{\mathrm{b}}$ Resources for the Future

${ }^{\mathrm{c}}$ National Bureau of Economic Research

${ }^{\mathrm{d}}$ University of Maryland

We are grateful to Lint Barrage, Terry Dinan, Don Fullerton, Stephen Holland, and seminar participants at the NBER Summer Institute on Environmental and Energy Economics, the Northeast Workshop on Energy Policy and Environmental Economics, Resources for the Future, the University of New South Wales, and the University of Ottawa. xxx 


\begin{abstract}
Economists have tended to view cap and trade (or, more generally, emissions pricing) as more cost-effective than a clean energy standard (CES) for the purpose of reducing greenhouse gas emissions associated with electricity generation. This stems in part from the finding that, in terms of cost-effectiveness, a CES relies too much on emissions abatement through the channel of fuelswitching and too little on the channel of reduced electricity demand.

Recent research reveals, however, that the CES has an advantage over cap and trade in a different dimension. In a realistic economy with prior taxes on factors of production, the adverse "taxinteraction effect" is smaller under the CES than under the equivalent cap-and-trade program. This raises the possibility that the CES might not suffer an overall disadvantage relative to cap and trade on cost-effectiveness grounds.

This paper employs analytical and numerical general equilibrium models to assess the relative cost-effectiveness of the CES and an electricity-sector cap-and-trade program. These models reveal that a well-designed CES can be more cost-effective than cap and trade when relatively minor reductions in emissions are called for. Numerical simulations indicate that the costeffectiveness of the CES is sensitive to what is deemed "clean" electricity. To achieve maximal cost-effectiveness, the CES must offer significant credit to electricity generated from natural gas.
\end{abstract}




\section{Introduction}

Although there currently is little action on U.S. climate change policy at the Congressional level, such policy is being actively conducted by the Executive Branch - by the U.S Environmental Protection Agency under the auspices of the Clean Air Act. ${ }^{1}$ In addition, climate change policy is being pursued through various initiatives by several U.S. states. ${ }^{2}$

One important policy approach under consideration at the federal level is a Clean Energy Standard (CES). Such a standard was proposed by former senator Jeff Bingaman (D-N.M.) in the Clean Energy Standard Act of 2012. ${ }^{3}$ A CES establishes a minimum for the share of electricity purchased by electric utilities coming from “clean” sources. The CES thus aims to give a boost to clean electricity generation, such as generation from wind or solar thermal sources.

The CES is an example of an intensity requirement: it focuses on the ratio of inputs of clean electricity to total inputs of electricity to utilities. ${ }^{4}$ Economists give intensity standards mixed reviews in terms of their ability to reduce emissions. On the positive side, they tend to view intensity standards as superior (on cost-effectiveness grounds) to some conventional policy approaches: they appreciate the fact that, in contrast to specific technology mandates, intensity

\footnotetext{
${ }^{1}$ EPA action is called for as a result of the 2006 U.S. Supreme Court decision in Massachusetts v. EPA, the Obama administration's subsequent "endangerment finding” that carbon dioxide (and other greenhouse gases) endanger public health and welfare, and the consequent designation in 2010 of carbon dioxide as a pollutant for regulatory purposes under the Clean Air Act both for stationary and mobile sources.

${ }^{2}$ Twenty-nine states currently have implemented or committed to some form of a renewable electricity standard or renewable portfolio standard.

${ }^{3}$ Earlier CES proposals were contained in the Clean Energy Act of 2009 proposed by Senator Graham (R-S.C.) and the Practical Energy and Climate Plan of 2010 proposed by Senator Luger (R-Ind). On June 25, 2013 President Obama promised to introduce controls on $\mathrm{CO}_{2}$ emissions from coal-fired power plants under the authority granted to the EPA under the Clean Air Act. Such controls are formally similar to a CES in which natural-gas-fired and nonfossil-generated electricity receive credit and coal-fired electricity does not.

${ }^{4}$ Thus the CES is an input-oriented intensity requirement. So is a renewable fuel standard, which requires that the share of refiners' total fuel purchases represented by "green" fuels not fall below some minimum. Intensity requirements can apply to outputs as well; these are often termed "performance standards." Automobile fuel economy standards (floors on the miles per gallon) provide an example.
} 
standards give firms or facilities the flexibility to choose whatever production method meets the standard at lowest private cost.

On the negative side, economists tend to view intensity standards as less cost-effective than policies that simply establish a price on each unit of emissions, as is the case with emissions taxes or systems of tradable emissions allowances. As shown by Holland, Hughes, and Knittel (2009) and Fullerton and Metcalf (2001), input-based intensity standards are formally identical to the combination of an emissions tax and input subsidy, with the implied revenue-loss from the subsidy identical to the revenue gain from the tax. As discussed below, even if the intensity standard leads to the efficient ratio of use of clean to "dirty" (higher-polluting) production inputs, the subsidy component tends to promote inefficiently high demands for inputs in general, which sacrifices cost-effectiveness. ${ }^{5}$ Indeed, Holland et al. show that an intensity standard intended to promote the use of cleaner fuels in the gasoline blend can result in an increase in emissions from fuels - because it promotes an inefficiently high demand for gasoline in general.

This would suggest that, as a policy to reduce carbon dioxide emissions associated with the production of electricity, the CES is less cost-effective than a cap-and-trade program or carbon-based emissions tax applied to the electricity sector. However, theoretical work by Parry and Williams (2010) indicates that the CES might fare considerably better on cost-effectiveness grounds once one accounts for interactions with the tax system. Because of the subsidy component, the CES leads to a lower price of electricity than a cap-and-trade system (or carbon tax) that promotes the same emissions reduction. Apart from tax interactions, this would sacrifice cost-effectiveness, as lower electricity prices limit the extent that emissions are reduced through the channel of lower electricity demand. However, as indicated below, lower electricity prices have a virtue in the presence of tax interactions: they imply a smaller adverse "tax-interaction effect.” Theory suggests that this offsetting benefit could potentially make the CES nearly as costeffective as - or even more cost-effective than - the equivalent emissions price policy. ${ }^{6}$ The issue merits further analysis: as indicated below, prior theory does not account for other factors

\footnotetext{
${ }^{5}$ The CES can suffer a further disadvantage if it fails to provide incentives to utilities to switch optimally between non-fossil-generated, natural-gas-generated, and coal-generated electricity. We consider this issue below.

${ }^{6}$ The smaller price increases from intensity standards can confer another potential attraction of such standards relative to emissions taxes. Environmental regulations can lead to "emissions leakage" when they cause firms to migrate outside of the jurisdiction in which the regulation is imposed or when they cause consumers to shift demands toward emissions-intensive goods or services produced outside of that jurisdiction. Holland (2012) points out that the smaller price increases from intensity standards can help limit emissions leakage and thereby reduce costs per reduction in (overall) emissions.
} 
that can significantly affect the relative cost of the CES, and quantitative assessments have been lacking.

This paper employs analytical and numerical general equilibrium models to assess the costs of achieving given reductions in greenhouse gases (GHGs) under the CES. It compares the CES's costs with those under cap and trade (C\&T). We first employ an analytical model that compares the costs while taking account of tax-interactions as well as other incentive effects not considered in prior theoretical work. This model indicates that the relative cost-effectiveness depends on the nature and extent of prior tax-distortions, on the stringency of the CES policy, on substitutability between various forms of electricity generation, and on specifics of the CES policy design. We then apply a numerical general equilibrium model of the U.S. to obtain quantitative results and arrive at more specific policy conclusions. The numerical model combines details on the U.S. energy system with details on the U.S. tax system, thus permitting an assessment of the tax interactions. The numerical simulations yield quantitative assessments of how the relative cost of the two types of policy depends on the various factors identified by the analytical model.

The rest of the paper is organized as follows. Section 2 presents and applies the analytical model. Section 3 presents the numerical model, and Section 4 indicates the data used by that model. Section 5 describes the policy simulations and presents the simulation results. The final section offers conclusions.

\section{An Analytical Model}

This section presents a relatively simple analytical model that illustrates the tradeoffs between a CES and C\&T (or a carbon tax), along with key factors that determine the relative efficiency of these two instruments.

\subsection{The Model}

A representative agent consumes two private goods, $X$ and $Y$, and a public good $G$, and supplies capital $(K)$ and labor $(L)$. The agent's utility function is given by

$$
U(X, Y, G, K, L)
$$


where $U$ is continuous, quasi-concave, and twice-differentiable. This function is increasing in the first three arguments (the two private goods and the public good) and decreasing in the last two. In contrast with the next section's numerical model, which is dynamic and considers capital formation, this analytical model is static and thus ignores the dynamics of capital accumulation. For simplicity it assumes instead that the provision of capital causes disutility to the agent (in keeping with the disutility of postponing consumption, which cannot be explicitly represented in a static model). ${ }^{7}$ Thus, in this model, capital is very similar to labor. ${ }^{8}$

The agent's budget constraint is given by

$$
X+p_{Y} Y=\left(1-\tau_{L}\right) w L+\left(1-\tau_{K}\right) r K,
$$

where $p_{Y}$ is the price of good $Y, \tau_{Y}, \tau_{L}$ and $\tau_{K}$ are the tax rates on $Y$, labor income and capital income, and $w$ and $r$ are the prices of labor and capital (i.e., the wage and rate of return). Good $X$ is the numéraire, so its price is normalized to one.

The agent maximizes utility (1) subject to the budget constraint (2), taking prices, tax rates, and the quantity of the public good as given. This yields the consumer first-order conditions:

$$
U_{X}=\lambda ; \quad U_{Y}=p_{Y} \lambda ; \quad-U_{K}=\left(1-\tau_{K}\right) r \lambda ; \quad-U_{L}=\left(1-\tau_{L}\right) w \lambda,
$$

where $\lambda$ is the marginal utility of income.

Goods $X$ and $G$ are non-polluting. For simplicity we assume that they have identical production technologies. Thus, production of these goods is given by

$$
X+G=F_{X}\left(K_{X}, L_{X}\right)
$$

where $K_{X}$ and $L_{X}$ are the quantities of capital and labor used in production of $X$ and $G$. The production function for good $Y$ is similar, except that production of good $Y$ generates pollution (Z). ${ }^{9}$ Pollution, a joint product, is represented here as an input. Thus, the production of $Y$ follows

\footnotetext{
${ }^{7}$ Ignoring the dynamics of capital accumulation means that this analytical model misses some of the reasons why capital taxation can be more distortionary than labor taxation. But it can still model the implications of a case in which one factor is subject to a more distortionary tax than the other.

${ }^{8}$ The model's results are identical under several alternative specifications or interpretations. One alternative is to specify capital supply as fixed and treat capital as having non-market (i.e., untaxed) uses. In that case, the disutility from supplying capital to the market would represent the cost of reducing the amount of capital devoted to those non-market uses. Similarly, the disutility from labor supply could represent disutility from working, or could represent the cost of giving up some non-market uses of time. A further alternative is to view $K$ not as capital, but as a second type of labor. In all of these cases the main results of the model would remain unchanged.

${ }^{9}$ The model does not capture the harmful effects of pollution. This has no effect on comparisons between the CES
} 


$$
Y=F_{Y}\left(K_{Y}, L_{Y}, Z\right)
$$

Both production functions are quasi-concave and twice-differentiable, and exhibit constant returns to scale. Pollution is not priced by the free market but is subject to an emissions tax, $\tau_{Z}$. Production of good $Y$ is also subject to a tax at the rate $\tau_{Y}$. Both industries are perfectly competitive; hence firms take all prices as given while maximizing profits. This implies the following first-order conditions for production of $X$ and $G$

$$
\partial F_{X} / \partial K_{X}=r ; \partial F_{X} / \partial L_{X}=w
$$

and for production of $Y$

$$
\partial F_{Y} / \partial K_{Y}=r /\left(p_{Y}-\tau_{Y}\right) ; \quad \partial F_{Y} / \partial L_{Y}=w /\left(p_{Y}-\tau_{Y}\right) ; \quad \partial F_{Y} / \partial Z=\tau_{Z} /\left(p_{Y}-\tau_{Y}\right) .
$$

The market for capital must clear (i.e., capital supplied must equal capital used in production)

$$
K=K_{X}+K_{Y}
$$

and the same is true for labor

$$
L=L_{X}+L_{Y} .
$$

The government uses tax revenue to finance provision of the public good. ${ }^{10}$ The government budget constraint follows

$$
\tau_{Y} Y+\tau_{Z} Z+\tau_{L} w L+\tau_{K} r K=G .
$$

Taken together, equations (1) through (10) implicitly define utility, all prices, and all quantities as functions of the four tax rates. The CES and C\&T can each be represented as a revenue-neutral combination of an increase in the pollution $\operatorname{tax}\left(\tau_{Z}\right)$ and a reduction in one of the other tax rates. As indicated in the introduction, the CES is equivalent to a pollution tax combined with a negative tax (i.e., a subsidy) on good $Y$. And under the assumption that the permits are auctioned and the revenue used to reduce taxes on capital and/or labor income, C\&T is equivalent to a pollution tax combined with a reduction in $\tau_{K}$ and/or $\tau_{L}$.

Taking a total derivative of utility (1) with respect to $\tau_{Z}$, substituting in the consumer first-order conditions (3), subtracting total derivatives of the production functions (4) and (5) with respect to $\tau_{Z}$, substituting in the firm first-order conditions (6) and (7), substituting in total

and C\&T because in all cases we compare policies that yield the same reductions in emissions.

\footnotetext{
${ }^{10}$ The model's results would be identical if government revenue (or a portion of that revenue) were instead spent on a transfer to the representative agent, as long as the real purchasing power of that transfer is held constant.
} 
derivatives of the factor-market clearing conditions (8) and (9) and the government budget constraint (10) with respect to $\tau_{Z}$, and rearranging yield the following equation for the marginal change in welfare for a marginal change in either the CES or C\&T:

$$
\frac{1}{\lambda} \frac{d U}{d \tau_{Z}}=\tau_{Z} \frac{d Z}{d \tau_{Z}}+\tau_{Y} \frac{d Y}{d \tau_{Z}}+\tau_{K} \frac{d(r k)}{d \tau_{Z}}+\tau_{L} \frac{d(w L)}{d \tau_{Z}} .
$$

This equation shows that the money-equivalent change in utility is equal to the sum of four terms, each of which represents the effect of a particular distortion. Each of these terms is equal to the size of the distortion (i.e., the tax rate) times the change in quantity in the distorted market. In each case, the tax puts a wedge between the marginal social cost and marginal social benefit for the taxed good, and thus any change in quantity has a corresponding effect on welfare.

\subsection{Effects of Cap \& Trade}

Here we exploit the fact that cap and trade is equivalent to a pollution tax combined with a reduction in $\tau_{K}$ and/or $\tau_{L}$. In this case, the $\frac{d}{d \tau_{Z}}$ terms will include the effect of the change in $\tau_{Z}$ and the effects of the changes in $\tau_{K}$ and/or $\tau_{L}$. Under cap and trade there is no tax or subsidy on $Y$. Thus, for this policy, (11) can be rewritten as

$$
\begin{aligned}
& \frac{1}{\lambda} \frac{d U}{d \tau_{Z}}=\tau_{Z} \frac{d Z}{d \tau_{Z}}+\tau_{K} \frac{\partial(r k)}{\partial \tau_{Z}}+\tau_{L} \frac{\partial(w L)}{\partial \tau_{Z}}+\frac{d \tau_{K}}{d \tau_{Z}}\left[\tau_{K} \frac{\partial(r K)}{\partial \tau_{K}}+\tau_{L} \frac{\partial(w L)}{\partial \tau_{K}}\right] \\
& +\frac{d \tau_{L}}{d \tau_{Z}}\left[\tau_{K} \frac{\partial(r K)}{\partial \tau_{L}}+\tau_{L} \frac{\partial(w L)}{\partial \tau_{L}}\right]
\end{aligned} .
$$

The first term on the right-hand side of (12) is the direct cost of the policy: the cost that comes from the effect on emissions (which is the same as the first term in (11)). The next two terms are what Goulder (1995) referred to as the "tax-interaction" effect: the welfare effect that arises when environmental policy distorts factor markets by altering real returns to these factors. The final two terms are the "revenue-recycling" effect: the welfare effect of using revenue from environmental policy to finance tax rate cuts for distortionary taxes.

To aid in interpretation of equation (12), it is useful to define the marginal cost of public funds (MCPF) for the taxes on capital and labor. The MCPF for a given tax is the marginal 
welfare cost per dollar of incremental revenue raised using a given tax. The MCPF for the capital and labor tax are

$$
\eta_{K}=\frac{r K}{r K+\tau_{K} \frac{\partial(r K)}{\partial \tau_{K}}+\tau_{L} \frac{\partial(w L)}{\partial \tau_{K}}}
$$

and

$$
\eta_{L}=\frac{w L}{w L+\tau_{K} \frac{\partial(r K)}{\partial \tau_{L}}+\tau_{L} \frac{\partial(w L)}{\partial \tau_{L}}}
$$

respectively. In each of these expressions, the numerator is the cost to the representative agent of a marginal increase in the tax, while the denominator is the marginal revenue from that tax increase. Thus, the ratio is the MCPF. ${ }^{12}$

Using (13) and (14), (12) can be rewritten as

$$
\frac{1}{\lambda} \frac{d U}{d \tau_{Z}}=\tau_{Z} \frac{d Z}{d \tau_{Z}}+\eta_{R}\left[\tau_{K} \frac{\partial(r k)}{\partial \tau_{Z}}+\tau_{L} \frac{\partial(w L)}{\partial \tau_{Z}}\right]+\left(\eta_{R}-1\right)\left(Z+\tau_{Z} \frac{d Z}{d \tau_{Z}}\right),
$$

where $\eta_{R}$ is the MCPF for the mix of tax cuts enabled by the pollution tax revenue. This provides a measure of how large a welfare gain those tax cuts will generate (i.e., how large the gain from the revenue-recycling effect will be). This is a weighted average of the MCPFs of the capital and labor taxes; it is given by

$$
\eta_{R}=\alpha_{K} \eta_{K}+\alpha_{L} \eta_{L}
$$

where $\alpha_{K}$ and $\alpha_{L}$ are the shares of marginal revenue devoted to cutting capital and labor taxes, respectively (note that we assume all revenue is used for cutting one tax or the other, implying that $\left.\alpha_{K}+\alpha_{L}=1\right)$.

As with expression (12), expression (15) can be divided into a direct effect (the first term), a tax-interaction effect (the second term), and a revenue-recycling effect (the third term). Under the assumption that $X$ and $Y$ are separable in utility from $K$ and $L$, the tax-interaction effect term can be simplified, and thus equation (15) can be rewritten as

$$
\frac{1}{\lambda} \frac{d U}{d \tau_{Z}}=\tau_{Z} \frac{d Z}{d \tau_{Z}}-\eta_{R}\left(\frac{\eta_{Z}-1}{\eta_{Z}}\right) Z+\left(\eta_{R}-1\right)\left(Z+\tau_{Z} \frac{d Z}{d \tau_{Z}}\right)
$$

\footnotetext{
12 Each expression is a "non-environmental” MCPF, one that ignores any welfare effects stemming directly from policy-induced changes in emissions or environmental quality.
} 
where $\eta_{I Z}$ is again a weighted average of the MCPFs of the capital and labor taxes, with the weights corresponding to how much taxing $Z$ affects the real returns to capital and labor. Thus,

$$
\eta_{I Z}=\gamma_{Z K} \eta_{K}+\gamma_{Z L} \eta_{L}
$$

where $\gamma_{Z K}$ and $\gamma_{Z L}$ are the shares of the burden of $\tau_{Z}$ that fall on capital and labor, respectively (and where $\gamma_{Z K}+\gamma_{Z}=1$ ).

The underlying effects that determine the relative magnitudes of $\gamma_{Z K}$ and $\gamma_{Z L}$ are the same as the effects that determine the relative incidence on capital and labor of a pollution tax, a problem previously studied by Fullerton and Heutel (2007). ${ }^{13}$ Most notably, $\gamma_{Z K}$ tends to be higher if capital is more complementary to pollution than labor is (i.e., when reducing pollution per unit of output implies a shift toward more labor-intensive production) or if the polluting good is relatively capital intensive. In those cases, the burden of the pollution tax tends to fall more on capital (as shown by Fullerton and Heutel), and thus the tax interaction effect here is also skewed more toward capital.

Equation (17) shows the three effects that determine the overall cost of emissions pricing. The first term, the direct cost of reducing emissions, is straightforward: it equals firms' marginal abatement $\operatorname{cost}\left(\tau_{Z}\right.$, because firms will abate emissions up to the point where their marginal cost of abatement equals the tax rate) times the marginal change in emissions caused by the policy.

The second term, the tax-interaction effect, depends on the quantity of pollution (the greater the quantity of pollution, the more of a burden a given pollution tax will have) and on $\eta_{I Z}$ (to the extent that the pollution tax burden falls on highly distorted factors of production, the welfare loss from the tax interaction effect will be larger). Perhaps surprisingly, it also depends on $\eta_{R}$ : the tax-interaction effect implies a loss of government revenue (discouraging the supply of capital and/or labor causes a drop in the revenue from taxes on those factors), and thus implies that the rates of those other taxes cannot be cut by as much.

The third term, the revenue-recycling effect, is equal to the MCPF for the mix of taxes that are cut $\left(\eta_{R}\right)$, times the marginal revenue from the pollution tax. This is intuitive: the more

\footnotetext{
${ }^{13}$ The exact expressions for the $\gamma$ terms differ slightly from the results in Fullerton and Heutel's model, because that paper's model assumed that both capital and labor supply are fixed, whereas this model allows both to vary. But the underlying effects are identical.
} 
revenue the pollution tax raises or the more distortionary the taxes are that are cut, the bigger the gain.

As will be shown in the next section, these effects also determine the cost of the CES and thus the difference in costs between policies. The CES has a higher direct cost and raises no revenue (thus generating no beneficial revenue-recycling effect), but because it generates a smaller tax-interaction effect, it can still be more cost-effective. As we indicate below, the difference in costs between the two policies will depend on magnitudes of the differences in the direct cost and tax-interaction terms between the two policies, and on the size of the revenuerecycling term.

\subsection{Effects of a Clean Energy Standard}

Here we exploit the fact that the clean energy standard is equivalent to a pollution tax combined with a negative tax on (i.e., a subsidy to) good $Y .{ }^{14}$ In this case the $\frac{d}{d \tau_{Z}}$ terms will include the effect of the increase in $\tau_{Z}$ and the decrease in $\tau_{Y}$. In addition, these terms will also include the effects of changes in $\tau_{K}$ and/or $\tau_{L}$. This might at first seem strange, since the CES does not raise any revenue. But there still may be changes in the tax rates on capital and labor in this case because the CES may affect the quantities of capital and labor, which indirectly affects revenue and requires offsetting tax rate changes in order to keep total government revenue constant. In light of this, (11) can be rewritten using the MCPF expressions (13) and (14) to give

$$
\frac{1}{\lambda} \frac{d U}{d \tau_{Z}}=\tau_{Z} \frac{d Z}{d \tau_{Z}}+\tau_{Y} \frac{d Y}{d \tau_{Z}}+\eta_{R}\left\{\tau_{K} \frac{\partial(r k)}{\partial \tau_{Z}}+\tau_{L} \frac{\partial(w L)}{\partial \tau_{Z}}+\frac{d \tau_{Y}}{d \tau_{Z}}\left[\tau_{K} \frac{\partial(r k)}{\partial \tau_{Y}}+\tau_{L} \frac{\partial(w L)}{\partial \tau_{Y}}\right]\right\} .
$$

This expression parallels expression (15) for the C\&T case. The first two terms on the right-hand side are the direct welfare effect of the CES, which comes from how the CES affects pollution

\footnotetext{
${ }^{14}$ One implication of this is that if the use of revenue from a pollution tax can be optimized over a sufficiently broad range of different recycling options, then a pollution tax (or auctioned cap-and-trade) will always be at least as efficient as a CES. The reason is simple: imposing a pollution tax and recycling the revenue to subsidize the polluting good $(Y)$ is equivalent to a CES. Hence if revenue-recycling is optimized over a set of possible recycling options that includes a subsidy to $Y$, the outcome must be at least as efficient as a CES. In this section, however, we are examining the effect of a range of different recycling options that are not necessarily optimal. Arguably, what we consider are more realistic and relevant to policy discussions.
} 
emissions and the quantity of the polluting good. The third term (i.e., the rest of the right-hand side) is the tax-interaction effect.

This tax-interaction effect can be broken into two pieces, corresponding to the effect of the emissions-tax component of the CES and the effect of the output-subsidy component (which appear in (19) as the term in parentheses times the first two terms in the curly brackets and times the third term in the curly brackets, respectively). The expression for the first (emissions-tax) component of the CES is the same as the one for the tax-interaction effect in the C\&T case. The expression for the second (output-subsidy) component is analogous, though it will typically have the opposite sign, implying a welfare gain, not a loss, because it is caused by a subsidy, not a tax. As a result, the tax-interaction effect is generally more positive (i.e., a smaller welfare loss or larger gain) for the CES than for C\&T. However, in contrast with the C\&T case, the CES does not produce any gain from the revenue-recycling effect.

As in the C\&T case, under the assumption that $X$ and $Y$ are separable in utility from $K$ and $L$, this equation can be further rewritten as

$$
\frac{1}{\lambda} \frac{d U}{d \tau_{Z}}=\tau_{Z} \frac{d Z}{d \tau_{Z}}+\tau_{Y} \frac{d Y}{d \tau_{Z}}-\eta_{R}\left(\frac{\eta_{I Z}-1}{\eta_{I Z}}\right) Z-\eta_{R}\left(\frac{\eta_{I Y}-1}{\eta_{I Y}}\right) Y \frac{d \tau_{Y}}{d \tau_{Z}} .
$$

where $\eta_{I Y}$ is analogous to $\eta_{I Z}$, but with the weights depending on the shares of the burden of $\tau_{Y}$ rather than $\tau_{Z}$. Just as in the C\&T case the effects that determine those relative weights are the same as those that determine the relative incidence of the environmental policy on capital and labor. ${ }^{15}$ Note that the weights underlying $\eta_{I Y}$ are determined not by the total incidence of the CES on capital and labor, but rather by the incidence of the subsidy component of the CES (the incidence of the tax component of the CES is reflected in the weights that determine $\eta_{I Z}$ ). Thus, for $\eta_{I Y}$ the weights depend primarily on the relative factor intensity in production of the polluting good (the relative complementarity with pollution, which was important for the weights in $\eta_{I Z}$, is not important for $\eta_{I Y}$ ).

\subsection{Comparing Marginal Costs under the Two Policies}

\footnotetext{
${ }^{15}$ In this case, the relevant prior paper on these effects is Fullerton and Heutel (2010), which focuses on the incidence of environmental mandates such as the CES.
} 
In order to compare the costs under the two policies, it is useful first to convert the expressions for marginal welfare changes into expressions for the marginal cost per unit of

emissions reductions. In each case, this is accomplished by dividing through by $\frac{d Z}{d \tau_{Z}}$. For the

C\&T case (starting from equation (17)), this gives

$$
M C_{C T}=\tau_{Z}-\eta_{R}\left(\frac{\eta_{Z}-1}{\eta_{Z}}\right) \frac{Z}{d Z / d \tau_{Z}}+\left(\eta_{R}-1\right)\left(\frac{Z+\tau_{Z} d Z / d \tau_{Z}}{d Z / d \tau_{Z}}\right),
$$

and for the CES case (starting from equation (20)), it gives

$$
M C_{C E S}=\tau_{Z}+\tau_{Y} \frac{d Y}{d \tau_{Z}} \frac{d Y / d \tau_{Z}}{d Z / d \tau_{Z}}-\eta_{R}\left(\frac{\eta_{Z}-1}{\eta_{Z}}\right) \frac{Z}{d Z / d \tau_{Z}}-\eta_{R}\left(\frac{\eta_{I Y}-1}{\eta_{I Y}}\right) \frac{Y d \tau_{Y} / d \tau_{Z}}{d Z / d \tau_{Z}} .
$$

We can then use these expressions to look at key determinants of the relative marginal costs of cap \& trade versus a clean electricity standard.

\subsubsection{Policy Stringency:}

There are two main ways in which the stringency of the policy (i.e., the amount of emissions reductions achieved) will affect the relative costs of the policies. Both tend to favor $\mathrm{C} \& \mathrm{~T}$ as the policy becomes more stringent. The first is well-known from prior work that ignores general-equilibrium effects: the direct costs tend to be higher under CES, because the CES does much less to reduce consumption of the polluting good, and the magnitude of that disadvantage grows as the policy becomes more stringent. Thus, the sum of the first two terms in (22) will be larger than the first term in (21), and that difference will tend to grow as the policies become more stringent.

The second reason is that as policy becomes more stringent, the direct cost terms become more important relative to the general-equilibrium terms (the tax-interaction and revenuerecycling effects). This is clear from examining (21) and (22): the direct-cost terms are proportional to $\tau_{Z}$ and $\tau_{Y}$, which are initially zero and increase as the policies become more stringent. In contrast, the general-equilibrium terms depend on $Z$ and $Y$, which will tend to shrink as the policies become more stringent. This means that increasing stringency will favor whichever policy fares worse with these general-equilibrium terms. In general, that could be either policy. But for cases in which the overall costs of the two policies are similar, that will be C\&T: because C\&T has lower direct costs, if the overall costs are similar between the two 
policies, then it must be because the general-equilibrium terms are more favorable to CES. Thus, a more stringent policy, by making those terms relatively less important, will tend to favor C\&T.

\subsubsection{Level of Pre-Existing Taxes:}

Higher pre-existing tax rates will tend to increase all of the $\boldsymbol{\eta}$ terms, thus magnifying the importance of the general-equilibrium terms. Thus, higher pre-existing taxes will tend to favor whichever policy fares better with those general-equilibrium terms. Again, in general this could be either policy, but for cases in which the overall costs of the two policies are similar, the CES must fare better with the general-equilibrium terms. Thus, in those cases, higher pre-existing tax rates will tend to favor the CES.

\subsubsection{Average MCPF of the Taxes That Are Reduced Using C\&T Revenue:}

C\&T will tend to fare better when the revenue it generates is used to cut a more distortionary tax than when it is used to cut a less distortionary tax. This is evident in equation (21): a higher $\eta_{R}$ boosts the magnitude of the revenue-recycling term relative to the taxinteraction term. The intuition here is obvious: cutting a more distortionary tax provides a bigger efficiency gain than cutting a less distortionary tax. No such effect shows up for the CES, which doesn’t raise revenue.

\subsubsection{MCPF for the Factor That Is More Intensively Used in Production of the Polluting Good:}

A CES will tend to fare better when the tax on the factor that is more intensively used in production of the polluting good is more distortionary (more generally, if $\gamma_{Y K}>\gamma_{Y L}$, then a higher $\eta_{K}$ relative to $\eta_{L}$ will tend to favor the CES, but relative factor intensity is the most important determinant of the $\gamma$ terms). This is evident from examining the last term in (22): that term lowers the cost of the CES, and a larger $\eta_{I Y}$ will increase the magnitude of that term relative to other terms. The CES's implicit subsidy for the polluting good tends to lower the cost from the tax-interaction effect, and that becomes more important when the tax on the factor more tightly linked to that polluting good is particularly distortionary. 


\subsubsection{Factor Intensity in Production of the Polluting Good for the More Distorted Factor:}

The CES will also tend to fare better when the polluting good is more tightly connected to

the factor subject to the more distortionary tax (e.g., if $\eta_{K}>\eta_{L}$, then a higher $\gamma_{Y K}$ will tend to favor CES). This arises for the same reason as the previous result: this tends to magnify the taxinteraction-effect advantage of the CES by boosting $\eta_{I Y}$. One highly important influence on $\gamma_{Y K}$ and $\gamma_{Y L}$ is the factor intensity in production of $Y$ : the more capital-intensive $Y$ is, the higher $\gamma_{Y K}$ will be, while the more labor-intensive $Y$ is, the higher $\gamma_{Y L}$ will be.

\subsubsection{Relative Importance of Reductions in Consumption of Polluting Goods versus Reductions in} Emissions per Unit of Polluting Goods Produced:

The CES will fare worse in cases where reducing consumption of polluting goods represents a relatively important channel for emissions reductions. As noted previously, the CES does not provide the right incentives to reduce consumption of polluting goods (the price increase for polluting goods is relatively small under the CES). Thus, to the extent that those reductions are an important channel for emissions reductions, the direct-cost disadvantage of the CES will be relatively large. This will occur, for example, in cases where the demand for polluting goods is relatively elastic.

Conversely, the CES will fare better in cases where reducing emissions per unit of polluting goods produced is a relatively important channel. In these cases, reducing consumption of polluting goods is relatively less important, which diminishes the direct-cost disadvantage of the CES. This will occur, for example, in cases with a high elasticity of substitution in production between polluting and non-polluting inputs.

\section{A Numerical Model}

Here we describe the structure and simulation results of an intertemporal general equilibrium model of the U.S. economy with international trade. The model generates paths of equilibrium prices, outputs, and incomes for the U.S. and the rest of the world under specified policy scenarios. The key agents are producers of various goods and services, a representative 
household, and the government. The model captures interactions among these agents, whose actions generate supplies and demands for various commodities and productive factors. It solves for all variables at yearly intervals beginning in the benchmark year 2010. ${ }^{16}$

The model combines a detailed U.S. tax system with a detailed representation of energy production and demand. The detail on taxes is key to capturing the interactions of environmental initiatives (like the CES or emissions pricing) and the tax system, as well as the significance of alternative ways to "recycle" potential any policy-generated revenues. Below we offer a brief description of the model. A detailed description is provided in Goulder and Hafstead (2013).

\subsection{Producer Behavior}

The model divides U.S. production into the 24 industry categories listed in Table 1 . This division gives particular attention to energy-related industries, as it identifies separately oil and natural gas extraction, coal mining, electric power, petroleum refining, and natural gas distribution. The specification of energy supply incorporates the nonrenewable nature of crude petroleum and natural gas and the transitions from conventional to backstop fuels. The electricity sector includes three types of generators, distinguishing coal-fired electricity generation, otherfossil electricity generation, and non-fossil electricity generation. ${ }^{17}$ It also includes "Electric Utilities” that purchase electricity from the generators on the wholesale market and are responsible for transmission and distribution of electricity.

General Specifications. In each industry, a nested production structure is employed with constant-elasticity of substitution functional forms at each nest. ${ }^{18}$ In all industries except the oil and natural gas extraction industry, production exhibits constant returns to scale. Each industry is modeled via a representative firm. Every industry produces a distinct output $(X)$, which is a

\footnotetext{
${ }^{16}$ In the model, agents face infinite planning horizons. To derive the necessary long-term information, under each policy experiment we first calculate steady-state (terminal) conditions and then employ those conditions in performing simulations over an interval of 100 years, by which time the economic path has converged very close to the steady-state (balanced) growth path.

${ }^{17}$ Non-coal fossil fuel generators primarily consist of natural gas fired generators. Non-fossil fuel generators include nuclear, hydro, solar, and wind generators.

${ }^{18}$ This nesting structure rules out the possibility that labor and capital differ in their degree of complementarity with pollution. This eliminates one effect that influences the relative weights on capital and labor in the tax interaction effect. While that effect could significantly influence the overall cost of both CES and C\&T, it does not importantly affect the cost difference between the policies.
} 
function of the inputs of capital $(K)$, labor $(L)$, an energy composite $(E)$, a non-energy (or materials) composite $(M)$, and the level of investment $(I)^{19}$ :

$$
X=f(K, g(L, h(E, M)))-\phi(I / K) \cdot I
$$

The energy composite is made up of the outputs of the energy industries, while the materials composite consists of the outputs of the other industries:

$$
\begin{aligned}
& E=E\left(\bar{x}_{1 a}+\bar{x}_{1 b}, \bar{x}_{2}, \ldots, \bar{x}_{8}\right) \\
& M=M\left(\bar{x}_{9}, \ldots, \bar{x}_{24}\right)
\end{aligned}
$$

where $\bar{x}_{i}$ is a composite of domestically produced good from industry $i$ and its foreign counterpart. ${ }^{20}$ Industry indices correspond to those in Table $1 .^{21}$

In the model, the nonrenewable nature of oil and gas stocks is captured by the specification of a reserve of the domestic oil \& gas resource. This reserve is reduced according to the amount of production (extraction) each year. Productivity in the oil \& gas industry is a decreasing function of the remaining reserve; hence extraction becomes more costly as reserves are depleted. In making profit-maximizing extraction decisions, oil and gas producers account for the effect of current production on future production costs. The domestic price of oil and gas is given by the exogenously specified world price of oil gross of tariffs. The model includes a "backstop fuels industry" that provides a perfect substitute for oil and gas. We assume that the technology for producing backstop fuels on a commercial scale becomes known only in the year 2020. We assume that backstop fuels have the same carbon content as oil and gas. ${ }^{22}$

\footnotetext{
${ }^{19}$ In each industry, capital $(K)$ is a constant-elasticity-of-substitution aggregate of structures and equipment.

${ }^{20}$ The functions $f, g$, and $h$, and the aggregation functions for the composites $E, M$, and $\bar{X}_{i}$ are CES and exhibit constant returns to scale.

${ }^{21}$ Indices $1 \mathrm{a}$ and $1 \mathrm{~b}$ represent the oil\&gas and synfuels industries, respectively. Synfuels are a "backstop technology" - a perfect substitute for oil\&gas. Only the oil\&gas industry is shown in Table 1 because synfuels production does not begin until 2020.

22 In reality, some potential backstops (e.g., shale oil) have higher carbon content than others (e.g., biofuels).
} 
The model incorporates technological change exogenously for each industry in the form of Harrod-neutral (labor-embodied) technological progress at the rate of one percent per year. ${ }^{23}$

Investment. In each industry, managers choose the level of investment to maximize the value of the firm. The investment decision takes account of the adjustment (or installation) costs represented by $\phi(I / K) \square$ in equation (23). $\phi$ is a convex function of the rate of investment, $I / K$,

$$
\phi(I / K)=\frac{(\xi / 2)(I / K-\delta)^{2}}{I / K},
$$

where $\delta$ is the rate of economic depreciation of the capital stock and $\xi$ is the marginal adjustment cost. ${ }^{24}$

The attention to adjustment costs distinguishes this model from most other economy-wide general equilibrium models. These costs imply that capital is imperfectly mobile across sectors. This allows the model to capture the different impacts of policy interventions on the profits of various industries. The law of motion for capital stocks for each industry is given by $K_{s+1}=(1$ $\delta) K_{s}+I_{s}$.

Profits and the Value of the Firm: For a firm in a given industry and given period of time, profits can be written as

$$
\begin{aligned}
\pi= & \left(1-\tau_{a}\right)\left[\bar{p} X-w\left(1+\tau_{L}\right) L-E M C O S T-r D E B T-T P R O P\right] \\
& +\tau_{a}(D E P L+D E P R)
\end{aligned}
$$

where $\tau_{a}$ is the corporate tax rate (or tax rate on profits), $\bar{p}$ is the per unit output price net of output taxes, $w$ is the wage rate net of indirect labor taxes, $\tau_{L}$ is rate of the indirect tax on labor, EMCOST is the cost to the firm of energy and materials inputs, $r$ is the gross-of-tax interest rate paid by the firm, $D E B T$ is the firm's current debt, TPROP is property tax payments, $D E P L$ is the current gross depletion allowance, and $D E P R$ is the current gross depreciation allowance.

Based on the cash-flow identity linking sources and uses of the firm's revenues, one can derive the following expression for the value of the firm $(V)$ :

\footnotetext{
${ }^{23}$ There is no explicit modeling of the invention of relatively new and evolving technologies such as carbon capture and storage. Such technologies may can have important long-run consequences. However, they are unlikely to affect the relative costs of the CES and C\&T, which is our focus here. .

${ }^{24}$ The variable $\phi$ captures the notion that there is an output loss associated with installing new capital as inputs are diverted to install the new capital.
} 


$$
V_{t}=\sum_{s=t}^{\infty}\left[\frac{1-\tau_{e}}{1-\tau_{v}} D I V_{s}-V N_{s}\right] \mu_{t}(s)
$$

This equation expresses the equity value of the firm as the discounted sum of after-tax dividends $(D I V)$ net of new share issues $(V N)$, where $\tau_{e}$ is the tax rate on dividend income and $\tau_{v}$ is the tax rate on capital gains. The discount factor is $\mu_{t}(s) \equiv \prod_{u=t}^{s}\left[1+\frac{\left(1-\tau_{b}\right) r_{u}}{1-\tau_{v}}\right]^{-1}$, where $\tau_{b}$ is the tax rate on interest income. In each period, managers choose investment levels as well as cost-minimizing inputs of labor and intermediate inputs to maximize this equity value.

\subsection{Household Behavior}

Household decisions are made by an infinitely-lived representative agent that chooses consumption, leisure, and savings in each period to maximize its intertemporal utility subject to an intertemporal budget constraint. The representative household has constant-relative-riskaversion utility over "full consumption" $C$, which is a constant-elasticity-of-substitution composite of consumption of goods and services $(\tilde{C})$ and leisure $(\ell) . \tilde{C}$ is a Cobb-Douglas composite of 17 consumer goods, $\bar{C}_{i} \cdot{ }^{25}$ In turn, each consumer good $\bar{C}_{i}$ is a constant-elasticityof-substitution composite of domestically and foreign produced goods. At each nest in the household's demand system, the household allocates its expenditure to obtain the composite associated with that nest at minimum cost.

\subsection{The Government Sector}

The public sector is represented by a single agent representing all levels of government. The government collects taxes, distributes transfers, purchases goods and services, and hires labor. Overall government expenditure is exogenous and increases at a constant rate, $g$, equal to the steady-state growth rate of the model. In the benchmark year, 2010, the government deficit is 2.6 percent of GDP. In the reference (status quo) simulation, the deficit-GDP ratio is approximately constant.

\footnotetext{
${ }^{25}$ Consumer goods are produced by combining outputs from the 25 industries in fixed proportions.
} 
In the policy experiments in this paper, we require that the real deficit and real government spending follow the same path as in the reference case. Thus, the time-profile of the government's real tax receipts in the CES and C\&T policy cases must be the same as in the

reference case. Revenue-neutrality is accomplished through lump-sum adjustments (i.e., rebating C\&T auction revenue via dividend checks) or through adjustments to the marginal tax rates applying to individual income (wages, interest income, dividends, and capital gains) or corporate profits.

\subsection{Foreign Trade}

Except for oil and gas imports, which are perfect substitutes for domestically produced oil and gas, imported intermediate inputs and consumer goods are imperfect substitutes for their domestic counterparts. Import prices are exogenous in foreign currency, but the domestic currency price changes with changes in the exchange rate. Export demands are modeled as functions of the foreign price of U.S. exports and the level of foreign income (in foreign currency). The foreign price is the price in U.S. dollars plus tariffs or subsidies, converted to foreign currency through the exchange rate. We impose the assumption of zero trade balance at each period of time. An exchange rate adjusts in each period to achieve balanced trade.

\subsection{Modeling the CES and C\&T}

The model offers a flexible treatment of both the CES and C\&T, allowing for alternative specifications as to the time-profile of the regulations and the industries covered.

CES. The CES policy applies to electric utilities, affecting their demands for electricity from the three types of generators (coal-fired, other fossil, and non-fossil).

Let $\bar{M}_{\boldsymbol{t}}$ denote the standard in period $t$. This constraint can be expressed by

$$
\frac{\sum_{i} a_{i} m_{i} x_{i t}}{\sum_{i} m_{i} x_{i t}} \geq \bar{M}_{t},
$$

The left-hand side is the ratio of "clean" electricity to total electricity demanded by the utility. The product $\boldsymbol{m}_{\boldsymbol{i}} \boldsymbol{x}_{\dot{\boldsymbol{u}}}$ in the numerator and denominator is the quantity of electricity purchased in period $t$ from generator $i$ by the electric transmission and distribution industry, where $x_{i t}$ is the quantity of fuel $i$ used at time $t$ (in units of the model's data) and $\boldsymbol{m}_{i}$ is a scaling coefficient that 
converts these units into megawatt hours. The symbol $a_{i}$ in the numerator is an indicator variable, equal to 1 if the generator type qualifies for the standard, and zero otherwise. ${ }^{26}$ Since $0<\bar{M}_{t}<1$, electricity from qualifying generators is subsidized while power from non-qualifying generators is taxed. $^{27}$

Producers minimize the cost of variable inputs subject to the constraint in (29). As shown in Appendix A, the constrained cost minimization problem can be replicated with an unconstrained cost minimization problem with the introduction of a revenue-neutral tax and subsidy scheme, where the utility receives a subsidy for the input of qualifying electricity and pays a tax on the input of non-qualifying electricity. Specifically, the tax on electricity from generator $i$ is given by

$$
\tau_{i t}=p_{t}^{c e s} m_{i}\left(\bar{M}_{t}-a_{i}\right)
$$

where $p_{t}^{c e s} \geq 0$ is the unique "price" such that satisfies $\sum_{i} \tau_{i t} x_{i t}=0$, thus making the tax-subsidy combination revenue-neutral.

$C \& T$. Cap-and-trade programs can vary along several dimensions, including the point of regulation, the nature of allowance allocation, and the presence or absence of provisions for allowance banking, borrowing, or offsets. To make a clean comparison between the costeffectiveness of the CES and C\&T programs, we introduce C\&T policies that match the point of regulation of the CES. Thus we only consider C\&T applied to the electric utility sector.

Additionally, to simplify the analysis, we primarily focus on policies with 100 percent auctioning without banking and borrowing or offset provisions. ${ }^{28}$

$E_{t}$, total emissions from electricity generation in period $t$, is expressed by

$$
E_{t}=\sum_{i} e_{i t} x_{i t}
$$

\footnotetext{
${ }^{26}$ If we allow for partial credits in the policy, then $a_{i} \in[0,1]$. President Obama's Clean Energy Standard proposal would give a half credit to electricity from natural-gas-fired power plants.

${ }^{27}$ If $a_{i} \in[0,1]$, then a generator is taxed if $a_{i}<\bar{M}_{t}$

${ }^{28}$ See Goulder, Hafstead, and Dworsky (2010) for an analysis of the trade-offs of auctioning vs. free allocation and a discussion on the cost-effectiveness of alternative policy designs such as banking and borrowing and carbon offsets.
} 
where $\boldsymbol{x}_{\boldsymbol{i} \boldsymbol{t}}$ again is the input (in model units) of generator $\mathrm{i}$ in period $t$, and $\boldsymbol{e}_{\boldsymbol{i t}}$ is the carbon intensity of generator $i$ in period $t$. Let $A_{t}$ represent the cap on total emissions from electricity generation in period $t$. The $\mathrm{CO}_{2}$ allowance price $p_{t}^{c}$ adjusts to equate aggregate emissions from electricity generation to the supply or cap.

Under a C\&T program implemented for the electric utility sector, the utility must hold and submit emissions allowances corresponding to the emissions generated by the production of the electricity it purchases. Let $p_{\text {iu }}$ denote the price to the utility of electricity produced by generator $i$, inclusive of the cost of emissions allowances associated with a unit of electricity. Then $p_{i u}$ can be expressed as:

$$
p_{\text {iu }}=p_{i}+p^{c} e_{i}
$$

where $p_{i}$ is production cost excluding the allowance cost. By affecting the $p_{i u}$ 's associated with electricity from each type of generator, C\&T influences the utilities’ demands for electricity from the various generators. ${ }^{29}$

\subsection{Equilibrium}

In each period, the requirements of equilibrium are that: (1) labor supply equals its demand, (2) savings equals investment, and (3) government expenditure equals tax revenue less the exogenously specified government deficit. Under simulations of C\&T policies, an additional equilibrium condition is that the aggregate demand for emissions allowances equals the aggregate supply (or cap).

In each period, market clearing is achieved through adjustments in output prices, the market interest rate, and lump-sum taxes or tax rates. ${ }^{30}$ In simulations of C\&T policies, the

\footnotetext{
${ }^{29} \mathrm{C} \& \mathrm{~T}$ also can affect the generators' production methods. The demand by utilities for from generator $i$ is a function of $p_{i u}$, which in turn is a function of the emissions associated with generator $i$ 's production. To the extent that a generator recognizes this connection, it has an incentive to reduce these associated emissions. For example, coalfired generators will have an incentive to reduce the amount of coal needed to generate a unit of electricity. In our simulations, we assume that generators are aware of this connection. Under these circumstances, a C\&T program applied to utilities according to the emissions embodied in the electricity they purchase is equivalent to a C\&T program imposed directly on the emissions from the generators. In our simulations of C\&T the cap is applied directly to the generators.

${ }^{30}$ By Walras's Law, the required number of equilibrating variables is one less than the number of equilibrium conditions. The numeraire is the nominal wage.
} 
allowance price adjusts such that the aggregate demand for allowances (given by aggregate emissions from covered sectors) equals the aggregate supply each period. We impose perfect foresight on all agents' expectations. ${ }^{31}$

\section{Data and Parameters}

Here we sketch some main components of the data and parameter inputs to the numerical model and their sources. Detailed documentation on the 2010 data set used for this analysis is provided in Goulder and Hafstead (2013) .

\subsection{Data}

Industry input and output flows were obtained primarily from the 2010 input-output tables from the U.S. Department of Commerce's Bureau of Economic Analysis (BEA). These tables were also the source for consumption, investment, government spending, employment, import, and export values by industry. Data on capital stocks by industry derive from BEA tables on the net stock of structures and equipment for each industry. Data on inputs, outputs, and capital are not available at a disaggregated level for the four electric power industries. To disaggregate the electric power industry, we must use a number of assumptions. We assume that non-fuel variable inputs are distributed across the four sectors according to revenue shares derived from the 2007 U.S. Census of Manufacturing. We distribute overall labor input across the generators based on the labor shares derived from the 2007 U.S. Census of Manufacturing, and distribute fixed capital based on total overnight installation costs by generator type from the U.S. EIA.

\subsection{Parameters}

\subsubsection{Production Parameters}

\footnotetext{
${ }^{31}$ To solve for the equilibrium, we apply a two-step algorithm similar to that of Fair and Taylor (Fair and Taylor, 1983). First we solve the model in each period for the market clearing prices, interest rates, and taxes given a set of expectations. We then iterate until we find expectations consistent with the intertemporal equilibrium condition of perfect foresight.
} 
The model employs production function elasticities of substitution derived from estimates by Dale Jorgenson and Peter Wilcoxen. We translate the Jorgenson-Wilcoxen estimates of parameters for translog cost functions into elasticities of substitution parameters to make them compatible with the constant-elasticity-of-substitution function form of our model. The capital adjustment cost parameters are based on Summers (1981). For the retail sector that purchases electricity from the three generators, in our central case we employ a value of 3 for the elasticity of substitution across electricity from the different generator types. Although electricity from different sources is highly substitutable, we assume less than perfect substitutability to account for regional capacity constraints. In the sensitivity analysis in Section 5.2 we employ other values for this important parameter.

\subsubsection{Household Parameters}

The elasticity of substitution in consumption between goods and leisure, $v$, is set to yield a compensated elasticity of labor supply of $0.4 .^{32}$ The intertemporal elasticity of substitution in consumption, $\sigma$, equals $.5 .^{33}$ The intensity parameter $\alpha_{C}$ is set to generate a ratio of labor time to the total time endowment equal to .44 . These parameters imply a value of 0.19 for the interest elasticity of savings between the current period and the next.

\subsubsection{Emissions Parameters}

Carbon dioxide emissions coefficients are set to match the distribution of emissions from energy consumption by source in 2010. ${ }^{34}$ Coefficients convert the input of coal and oil into emissions. $^{35}$

\footnotetext{
${ }^{32}$ This lies midway in the range of estimates displayed in the survey by Russek (1996).

${ }^{33}$ This value falls between the lower estimates from time-series analyses (e.g., Hall (1988) and the higher ones from cross-sectional studies (e.g., Lawrance (1991).

${ }^{34}$ Source: U.S. Energy Information Administration Annual Energy Review 2011.

${ }^{35}$ The aggregation of reported emissions sources (electric power, transportation, commercial, residential, and transportation) differs from the model industry aggregation. To match emissions by source, we make the following assumptions: a) the coal coefficient for all industries except coal fired electricity generators is equal; b) the oil coefficient for all industries except petroleum refining, other fossil electricity generation, and natural gas distribution are equal.
} 


\section{Results}

\subsection{Reference Case}

All simulations begin in the year 2010. We first perform a reference case simulation that assumes business-as-usual conditions and forms the reference path against which we measure the effects of policy shocks. Table 1 shows the levels of real output of each industry in the reference case in 2010, in billions of 2010 dollars.

Of key relevance to the CES and C\&T policies are the emissions levels and intensities of the various electricity generators. Table 2 offers this information. The emissions indicated are based on the carbon content of the fuels combusted in the generation process. As indicated in the table, coal-fired generation has by far the highest emissions intensity and represents the largest share of emissions among the generators. We attribute zero emissions to the non-fossil generators.

\subsection{Policy Results}

\subsubsection{CES and Cap-and-Trade Policies: Central Case Simulations}

We start with a focus on CES policies that are similar to those in the Obama/Bingaman proposal in terms of what qualifies as “clean” electricity. As in those proposals, non-fossilgenerated electricity is given full credit and natural-gas-fired electricity is given half credit. (Coal-fired generation is considered “dirty” and receives zero credit.) Later we consider alternative specifications where we vary the credit level received by natural-gas-fired generators.

We will use the term "CES ratio" to refer to the required minimal ratio of clean generation (in megawatt-hours) to total generation. In our simulations, the CES ratio begins with the business-as-usual ratio in 2013 and increases through time, ultimately settling at some targetvalue in the year 2035.

Figure 1 shows the three CES time-profiles on which we focus. The policies are designed to achieve 20, 30, and 40 percent cumulative emissions reductions in the time period from 2013 to 
2035. In 2035 and afterwards, the ratios of clean to total electricity under these policies are 59.4, 68.4 and 77.7 percent, respectively. ${ }^{36}$

Figure 2 displays the time-profile of $\mathrm{CO}_{2}$ emissions in the reference case and under the three CES policies. The kink at year 2035 reflects the fact that the ratios remain constant starting in that year. As a result, emissions no longer decline but instead increase with the growth rate of the economy.

As mentioned in subsection 3.5 above, the CES is equivalent to a revenue-neutral tax and subsidy program, where the utility's electricity purchase involves either a tax or subsidy depending on whether the electricity is produced through "clean" generation. Figure 3 displays the shadow tax and subsidy rates applying to the electricity from the three generators. For each generator $i$, these correspond to $\tau_{i t}$ in equation (30) above. From 2013 through 2035, the shadow tax on electricity from coal-fired generators tends to rise. This reflects the increasing stringency of the CES over time and the associated need to induce greater substitution away from coal-fired electricity. Starting in 2035, the CES ratio is held constant, and the shadow tax no longer increases. Indeed, it falls. The pattern for non-fossil-generated electricity is the opposite of that for coal-fired electricity. Because non-fossil-generation is deemed clean, it receives a subsidy. The subsidy is initially high and decreases over the medium term before increasing again through 2035. The shift from a decreasing subsidy to an increasing one tends to correspond to the shift of “other-fossil” electricity (principally natural-gas-fired) from a subsidy to a tax. In the central case simulations considered here, "other fossil” generators receive partial credit. In the initial years of the policy, the required CES ratio $\bar{M}_{t}$ is less than the partial credit, which from equation (30) implies that other-fossil-generated electricity receives a subsidy. Over time, the CES ratio $\bar{M}_{t}$ is increased. It eventually exceeds the credit and the subsidy becomes a tax.

To allow for a clean comparison of the CES and C\&T policies, the emissions caps for the electricity sector for each year are set to match the emissions that result from that sector under the CES policies. ${ }^{37}$ In these initial comparisons, the C\&T policy involves auctioning 100 percent of the emissions allowances, with revenues recycled through cuts in the marginal income tax rates.

\footnotetext{
${ }^{36}$ The most stringent policy is closest to the Obama/Bingaman proposal, which aimed to achieve a ratio of 80 percent by 2035 .

${ }^{37}$ An alternative is to match economy-wide emissions each year under the two types of policies. We find that the results for the relative costs of CES and C\&T are similar when we adopt this alternative.
} 
(Below we will assess how alternative methods of revenue-recycling affect the costs of the C\&T policy, absolutely and relative to the costs under the CES.)

Figure 4 compares the CES and C\&T policies in terms of their impacts on the present value of GDP over the interval 2013-2035. Except in the case with the least stringent CES, the GDP costs of the CES are greater than those of C\&T, although the disadvantage is small when the policies are not stringent. As indicated above, the CES does not require electric utilities to pay for the emissions that remain once they have met the required CES ratio. Hence their marginal costs of production and electricity prices are lower in the case of CES than in the C\&T case. As a result, the CES triggers less reduction in the demand for electricity than the C\&T policy, and it must rely more on fuel-substitution to achieve the needed emissions reductions. The results in Figure 4 suggest that this disadvantage of the CES is fully offset by the CES's advantage in producing a smaller tax-interaction effect.

Figure 5 also displays the relative costs of the two policies, in this case in terms of the equivalent variation welfare measure. Again the relative costs depend on stringency. Under the equivalent variation welfare measure, the CES is less costly at low levels of stringency. The results suggest that as stringency increases, the CES's disadvantage in terms of its inability to exploit the demand-reduction channel increases in importance relative to its advantage in terms of its lower tax-interaction effect.

Figure 6 contrasts the impacts of the CES and C\&T policies on the demand for electricity. Because electricity prices are higher under C\&T than CES, the quantity of electricity demanded is lower in the C\&T case. In the long run, the demand reduction is nearly 3.5 times as large as in the C\&T policy in the 20 percent emission reduction policy, and about 1.9 times larger in the 40 percent reduction policy.

Figure 7 displays the effect of the CES and C\&T policies on the price of the consumption bundle as the percentage change in price relative to the reference case for 2013-2110. ${ }^{38}$ Because C\&T raises electricity prices more, it has a more pronounced effect on the price level than the equivalent CES policy. The difference in the price increases is relatively small in the early years of the policy, but the difference is increasing over time as the policies become more stringent. These differing impacts in prices underlie the differences indicated earlier in the costs of the two

\footnotetext{
${ }^{38}$ The percent change in other aggregate prices, such as the price of the producer price index, displays a similar time-profile and pattern as the percent change in the price of the consumption bundle.
} 
policies. Cap and trade’s larger price impacts imply a larger tax-interaction effect. In Figure 7, the deviation in percentage increases in prices is largest for the most stringent policy, although the ratio of these percentage increases declines with stringency.

\subsubsection{Isolating the Tax-Interaction Effect}

We now examine results from counter-factual simulations in which we have altered the level of pre-existing taxes. This enables us to isolate and assess the impact of the tax-interaction effect, since the magnitude of the tax-interaction effect is positively related to the levels of such taxes.

Figure 8a compares the welfare costs of CES and C\&T under the scenarios that differ in terms of the pre-existing individual income taxes (taxes on wages, interest, and dividends). The comparisons are for policies involving intermediate stringency (30 percent cumulative emissions reductions over the interval 2013-2035). The CES policy offers other-fossil-generated electricity a half credit, as in the Obama/Bingaman proposal, and the C\&T policy involves auctioning of the emissions allowances, with revenues recycled lump-sum to households. ${ }^{39}$ Figure $8 \mathrm{~b}$ compares the same policies across scenarios differing in terms of pre-existing individual income taxes and corporate income tax rates.

As predicted by the analytical model, the level of welfare costs for both the CES and C\&T policies are increasing in the level of pre-existing taxes. Additionally, the ratio of the CES policy's welfare cost to that of the CES policy is decreasing in the size of pre-existing taxes. This confirms the relative advantage of the CES in terms of a smaller tax-interaction effect. These results are particularly magnified when corporate income taxes are included in Figure 8b, as corporate income taxes are more distortionary than personal income taxes in our model.

\subsubsection{Factor Intensities of the Electricity Sector}

The analytical model predicted that the CES will fare better when the polluting good is tightly tied to the factor subject to the more distortionary tax. In our model, capital is subject to

\footnotetext{
${ }^{39}$ For simplicity, in the simulations shown in Figure 8 revenue-neutrality is achieved through lump-sum recycling of the policy-generated revenues. As a result, the benefit associated with each dollar returned to the private sector is the same (one dollar), regardless of the level of pre-existing taxes. If instead the recycling were in the form of cuts in existing income tax rates, the value of the recycling would depend on the pre-existing marginal rates. This added dimension would unnecessarily complicate the analysis.
} 
the more distortionary tax, as taxes on individual and corporate capital income have a higher marginal excess burden than taxes on labor income. Thus the analytical model predicts that the ratio of the cost of the CES to that of C\&T will increase to the extent that the capital intensity of the electricity electric utility sector is reduced. To test this prediction, we run counter-factual simulations in which we reduce the capital intensity of the electric utility sector. ${ }^{40}$ Figure 9 shows that the welfare costs of both CES and C\&T are declining in the capital intensity of the utility sector. As predicted by the analytical model, the welfare costs of C\&T decline relatively more than the welfare costs of the corresponding CES policies because the tax on capital (through individual capital income and corporate income taxes) is more distortionary than the tax on labor.

\subsubsection{Alternative Cap-and-Trade Specifications}

In most of the C\&T policies considered above, emissions allowances were auctioned and the revenues were recycled through cuts in the marginal rates of personal income taxes. However, the method of revenue-recycling can affect the relative costs of C\&T and the CES. Figure 10 compares costs of $\mathrm{C} \& \mathrm{~T}$ and the CES under a range of revenue-recycling specifications for the C\&T policy. The case labeled "C\&T, Auctioning, Net MTR LK" is the case we have focused on earlier. "C\&T, Auctioning, Net MTR C" recycles revenues through cuts in corporate income taxes. "C\&T, Auctioning, Lump-Sum Rebates" refers to the case where revenues are returned to households lump sum. “C\&T, Free Allocation” refers to the case where all of the allowances are distributed free to generators.

The results in this figure reveal circumstances where the CES is less costly than C\&T. As prior studies have emphasized, ${ }^{41}$ the costs of $\mathrm{C} \& \mathrm{~T}$ increase when auction revenues are returned lump-sum (rather than via marginal rate cuts) or when allowances are given out free. As shown in these figures, when C\&T has either of these two features it is always more costly than the CES, even when the policy is not very stringent.

As shown in the analytical section, C\&T will tend to fare better when the revenue it generates is used to cut a more distortionary tax than when it is used to cut a less distortionary tax. The MCPF of individual income taxes is $\$ 1.17$ and the MCPF of corporate income taxes is $\$ 1.77$;

\footnotetext{
${ }^{40}$ To do this, we shift $\$ 200$ or $\$ 400$ billion from $\mathrm{K}$ to $\mathrm{L}$ in the 2010 dataset.

${ }^{41}$ See, for example, Parry and Oates (2000). and Goulder et al. (1999).
} 
therefore C\&T will be less costly when corporate income taxes are reduced as opposed to personal income taxes. Figure 10 shows that C\&T always performs better than CES when revenues are used to cut corporate tax rates.

\subsubsection{Alternative CES Specifications: Partial Credit for Natural Gas}

Figure 11 shows the ratio of welfare costs (CES/C\&T) under a range of credits to natural gas. ${ }^{42}$ As the credit received by natural gas generated electricity increases, the relative cost of CES decreases. The relative cost is minimized on the chart at about 0.8 for each level of stringency. ${ }^{43}$ If natural gas-fired electricity receives zero credit, the CES will not induce efficient substitution between the two carbon-based electricity generators. If natural gas-fired electricity receives a full credit, the CES will not induce efficient substitution between natural gas-fired electricity and renewables. In contrast to a CES, a C\&T system that charges a uniform price for $\mathrm{CO}_{2}$ emissions in theory will promote the most cost-effective generator-switching pattern. Currently, the EPA is developing rules for limiting $\mathrm{CO}_{2}$ emissions through Section 111(D) of the Clean Air Act. Our results on partial credits for natural gas suggest the most cost-effective rules will be ones that mimic the generator-switching patterns of a C\&T system. Rules that simply limit the amount of emissions per unit of electricity by fuel type, such as the rules that were proposed for new sources, would not promote efficient fuel switching.

\subsubsection{Further Sensitivity Analysis}

Figure 12 displays the welfare costs under alternative elasticities of labor supply. The lower elasticity is 0.3 and the higher elasticity is 0.5 . The welfare cost of achieving a given level of emissions reductions is increasing in the level of the elasticity of labor supply. ${ }^{44}$ However, the relative welfare cost of the CES policy to the C\&T policy is approximately constant across varying elasticities of labor supply.

Figure 13 displays the welfare costs under alternative elasticities of substitution across generators in the utilities' production function. In our central case, the value of this elasticity is 3.

\footnotetext{
${ }^{42}$ In each of the simulations here, revenues are recycled through cuts in personal income tax rates.

${ }^{43}$ Using 2010 emissions, the ratio of emissions per megawatt hour of other fossil electricity to coal-fired electricity is 0.42 . Thus, the "optimal” emissions intensity of other fossil electricity should be 0.58 . However, as shown by Lemoine (2013), welfare maximizing intensity ratings do not always reflect actual emissions intensities due to market interactions.

44 The CES target in 2035 is varied across alternative labor supply elasticities such that the level of emissions reductions is constant across policies.
} 
Here we consider values of 2 and 4 as well. As expected, both the level of welfare costs and the relative cost of CES to cap-and-trade is decreasing in the elasticity of substitution across generators. When the elasticity is high, it is easy to for electric utilities to substitute between generators and therefore the aggregate price increases and welfare losses will be reduced. As discussed, the CES relies more heavily on this substitution than C\&T, which makes more efficient use of the channel of reduced overall demand for electricity. Because of the greater weight attached to substitution under the CES, greater substitutability enhances the relative attractiveness of the CES policy. Symmetrically, lower substitutability reduces the relative attractiveness of CES.

\section{Conclusions}

In a realistic economy with prior taxes on factors of production, the CES has a potential attraction relative to an electricity-sector C\&T program: it produces smaller tax-interaction effect. This raises the possibility that the CES might not suffer a disadvantage relative to cap and trade on cost-effectiveness grounds.

This paper has employed analytical and numerical general equilibrium models to assess the relative cost-effectiveness of the CES and an electricity-sector C\&T program. Numerical simulations indicate that a well-designed CES is more cost-effective than C\&T (even when C\&T revenue is recycled to cut marginal tax rates) when relatively minor reductions in emissions are called for. To achieve maximal cost-effectiveness, the CES needs to offer partial credit to natural-gas-fired electricity. The CES can more easily overtake C\&T in terms of costeffectiveness when the C\&T program involves free allowance allocation or when revenues from auctioned allowances are rebated lump sum.

Although emissions pricing remains an exceptionally attractive vehicle for reducing greenhouse gas emissions, these results demonstrate that the advantage of such pricing in terms of cost-effectiveness is less clear once interactions with the tax system are taken into account. As climate change policy continues to evolve at the state and federal levels in the U.S., reducing emissions from coal-fired power plants is likely to remain a priority. States may increasingly rely on renewable portfolio standards (the state-level equivalent to a federal CES), and federal policy discussions may continue to consider the CES as well as emissions-pricing policies such as a 
federal carbon tax. In assessing these policy options, it is important to consider the interactions with the tax system, since as indicated here such interactions significantly affect their relative costs. 


\section{References:}

Fair, Raymond, and John Taylor, 1983. "Solution and Maximum Likelihood Estimation of Dynamic Nonlinear Rational Expectations Models." Econometrica 51(4): 1169-85.

Fullerton, Don, and Garth Heutel. 2007. "The General Equilibrium Incidence of Environmental Taxes." Journal of Public Economics 91(3-4):571-591.

Fullerton, Don, and Garth Heutel. 2010. "The General Equilibrium Incidence of Environmental Mandates." American Economic Journal: Economic Policy, 2(3): 64-89.

Fullerton, Don, and Gilbert E. Metcalf, 2001. "Environmental Controls, Scarcity Rents, and PreExisting Distortions." Journal of Public Economics 80(2 (May)): 249-67.

Goulder, Lawrence H., 1995. "Environmental Taxation and the 'Double Dividend:' A Reader's Guide." International Tax and Public Finance 2(2): 157-83.

Goulder, Lawrence H., and Marc A. C. Hafstead, 2013. "A Numerical General Equilibrium Model for Evaluating U.S. Energy and Environmental Policies: Model Structure and Data Documentation." Stanford University, Stanford, Calif.

Goulder, Lawrence H., Marc A. C. Hafstead, and Michael Dworsky, 2010. "Impacts of Alternative Emissions Allowance Allocation Methods under a Federal Cap-and-Trade Program." Journal of Environmental Economics and Management 60(3): 161-81.

Goulder, Lawrence H., Ian W. H. Parry, Roberton C. Williams III, and Dallas Burtraw, 1999. "The Cost-Effectiveness of Alternative Instruments for Environmental Protection in a Second-best Setting." Journal of Public Economics 72(3): 329-60.

Hall, Robert, 1988. "Intertemporal Substitution in Consumption." Journal of Political Economy 96(2): 339-57.

Holland, Stephen, Jonathan E. Hughes, and Christopher Knittel, 2009. "Greenhouse Gas Reductions under Low Carbon Fuel Standards?". American Economic Journal: Economic Policy 1(1): 106-46.

Holland, Stephen, 2012. "Emissions taxes versus intensity standards: Second-best environmental policies with incomplete regulation". Journal of Environmental Economics and Management 63(3): 375-87.

Lawrance, Emily, 1991. "Poverty and the Rate of Time Preference: Evidence from Panel Data." Journal of Political Economy 99(1): 54-77.

Lemoine, Derek, 2013. "Escape from Third-Best: Rating Emissions for Intensity Standards." University of Arizona Working Paper 12-03, September 2013. 
Parry, Ian W. H., and Roberton C. III Williams, 2010. "Moving U.S. Climate Policy Forward: Are Carbon Taxes the Only Good Alternative?" In Discussion Paper 11-02, Resources for the Future.

Parry, Ian W.H., and Wallace E. Oates, 2000. "Policy Analysis in the Presence of Distorting Taxes." Journal of Policy Analysis and Management 19(4): 603-14.

Russek, Frank S., 1996. "Labor Supply and Taxes." Working paper, Macroeconomics Division, Congressional Budget Office, Washington, D.C.

Summers, Lawrence H., 1981. "Taxation and Corporate Investment: A q-theory Approach." Brookings Papers on Economic Activity 1: 67-127. 
Table 1 . Output ${ }^{1}$ in 2010 by Industry in Reference Case

\begin{tabular}{lrr}
\hline Industry & Output & $\begin{array}{r}\text { Pct. of Total } \\
\text { Output }\end{array}$ \\
\hline \hline 1a. Oil and Gas Extraction & 272.2 & 0.7 \\
2. Electric Utilities & 441.0 & 1.2 \\
3. Coal-Fired Electricity Generation & 100.1 & 0.3 \\
4. Other Fossil Electricity Generation & 57.8 & 0.2 \\
5. Nonfossil Electricity Generation & 64.2 & 0.2 \\
6. Coal Mining & 79.5 & 0.2 \\
7. Natural Gas Distribution & 144.9 & 0.4 \\
8. Petroleum Refining & 573.4 & 1.5 \\
9. Agriculture and Forestry & 506.9 & 1.4 \\
10. Noncoal Mining & 69.6 & 0.2 \\
11. Water Utilities & 48.6 & 0.1 \\
12. Construction & $5,325.4$ & 14.4 \\
13. Food, Tobacco, and Beverages & 970.2 & 2.6 \\
14. Textiles & 186.7 & 0.5 \\
15. Wood and Paper Products & 456.4 & 1.2 \\
16. Chemicals and Misc. Nonmetal Products & $1,527.5$ & 4.1 \\
17. Primary Metals & 311.7 & 0.8 \\
18. Machinery & $2,247.2$ & 6.1 \\
19. Motor Vehicle Production & 719.9 & 1.9 \\
20. Transportation & 803.8 & 2.2 \\
21. Railroads & 143.1 & 0.4 \\
22. Information and Communication & $1,109.2$ & 3.0 \\
23. Services & $15,973.5$ & 43.1 \\
24. Owner-Occupied Housing & $4,918.1$ & 13.3 \\
\hline \hline I. & &
\end{tabular}

${ }^{1}$ In billions of 2010 dollars.

Table 2. Emissions and Emissions Intensities by Generator

\begin{tabular}{lccc}
\hline Generator & $\begin{array}{c}\text { Billions } \\
\text { MWh (2010) }\end{array}$ & Emissions $^{1}$ & $\begin{array}{c}\text { Emissions Per } \\
\text { MWh (2010) }\end{array}$ \\
\hline \hline Coal-Fired & 1.84 & 1.83 & 0.99 \\
Other Fossil & 1.04 & 0.43 & 0.42 \\
Nonfossil & 1.24 & 0.00 & 0.00 \\
\hline \hline
\end{tabular}

${ }^{1}$ In billions metric tons $\mathrm{CO}_{2}$. 
Figure 1. CES Ratio by Time and Stringency, 2013-2050

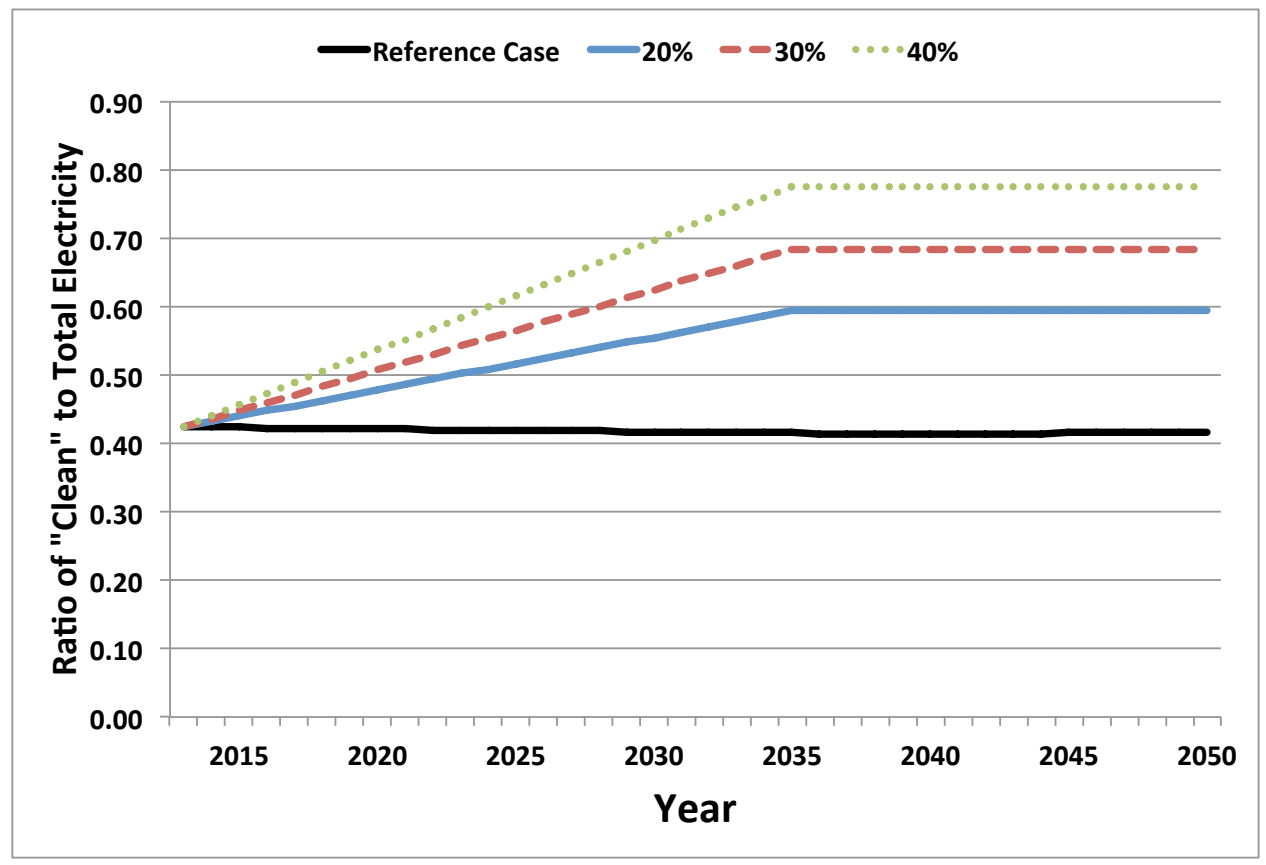

Figure 2. Emissions from Electricity Generation, 2013-2050

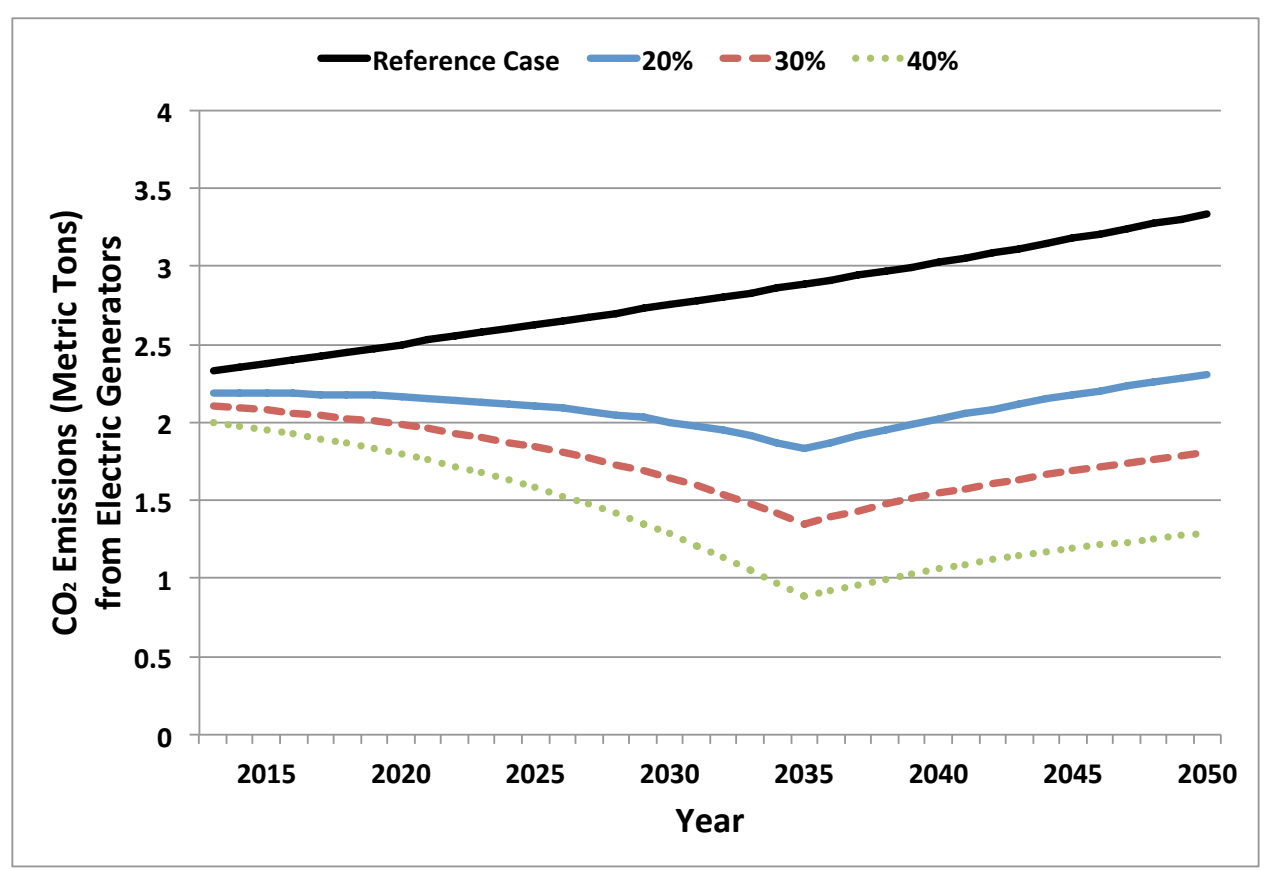


Figure 3. Shadow Tax/Subsidy on Electricity Generators

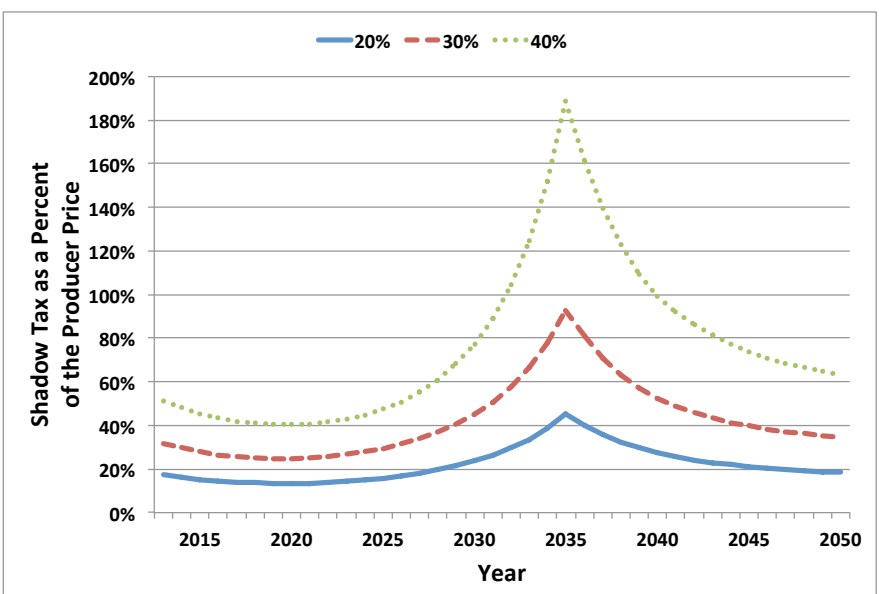

(a) Coal-Fired Generators

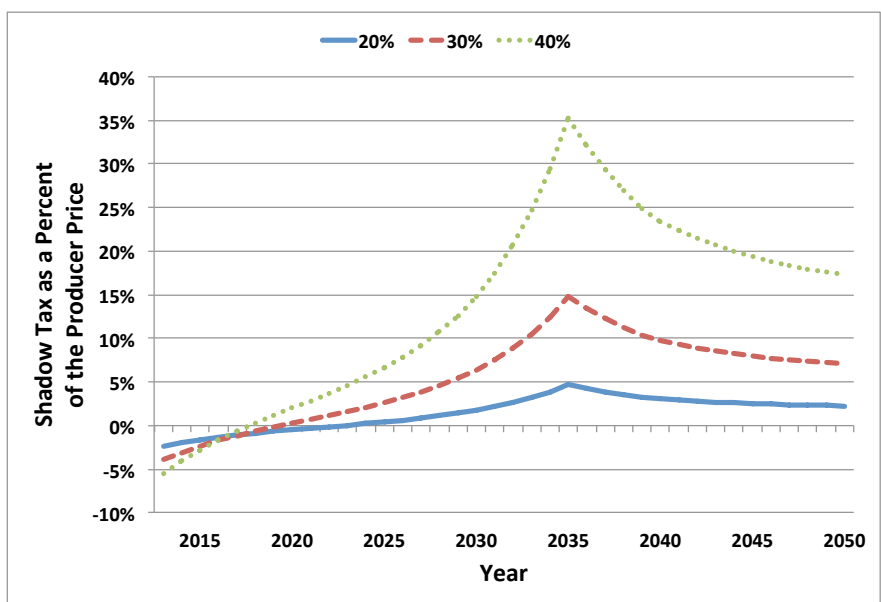

(b) Other-Fossil Generators

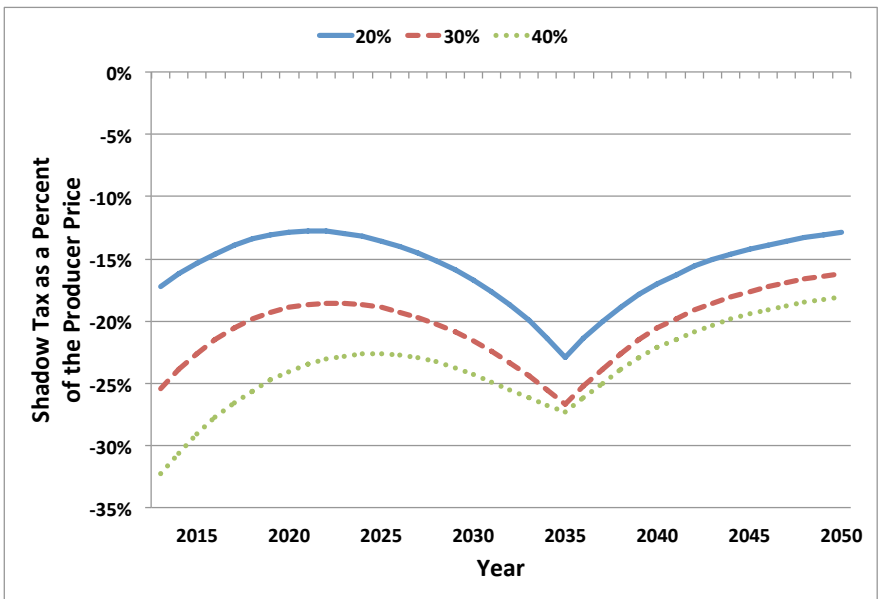

(c) Nonfossil Generators 
Figure 4. GDP Costs of CES and Cap and Trade

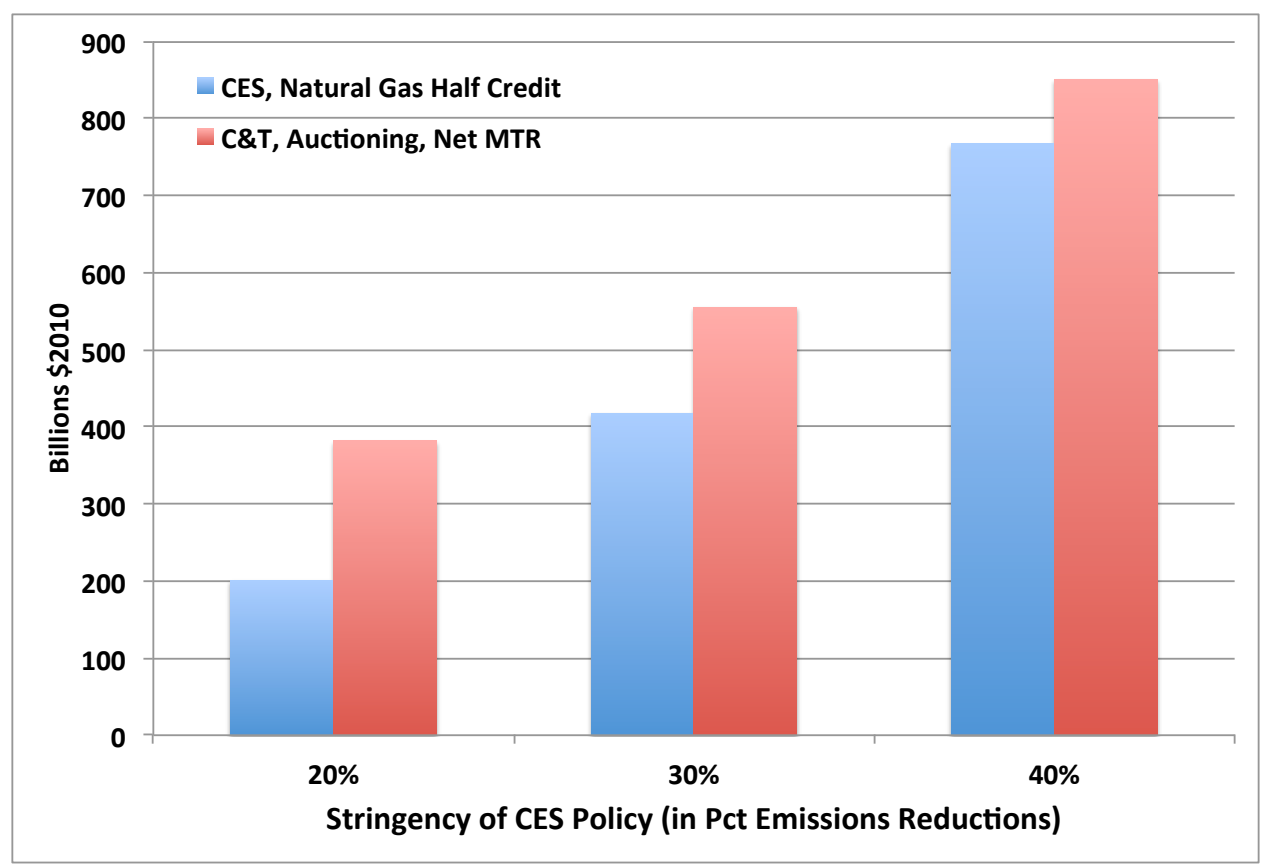


Figure 5. Welfare Costs of CES and Cap and Trade (Equivalent Variation Measure)

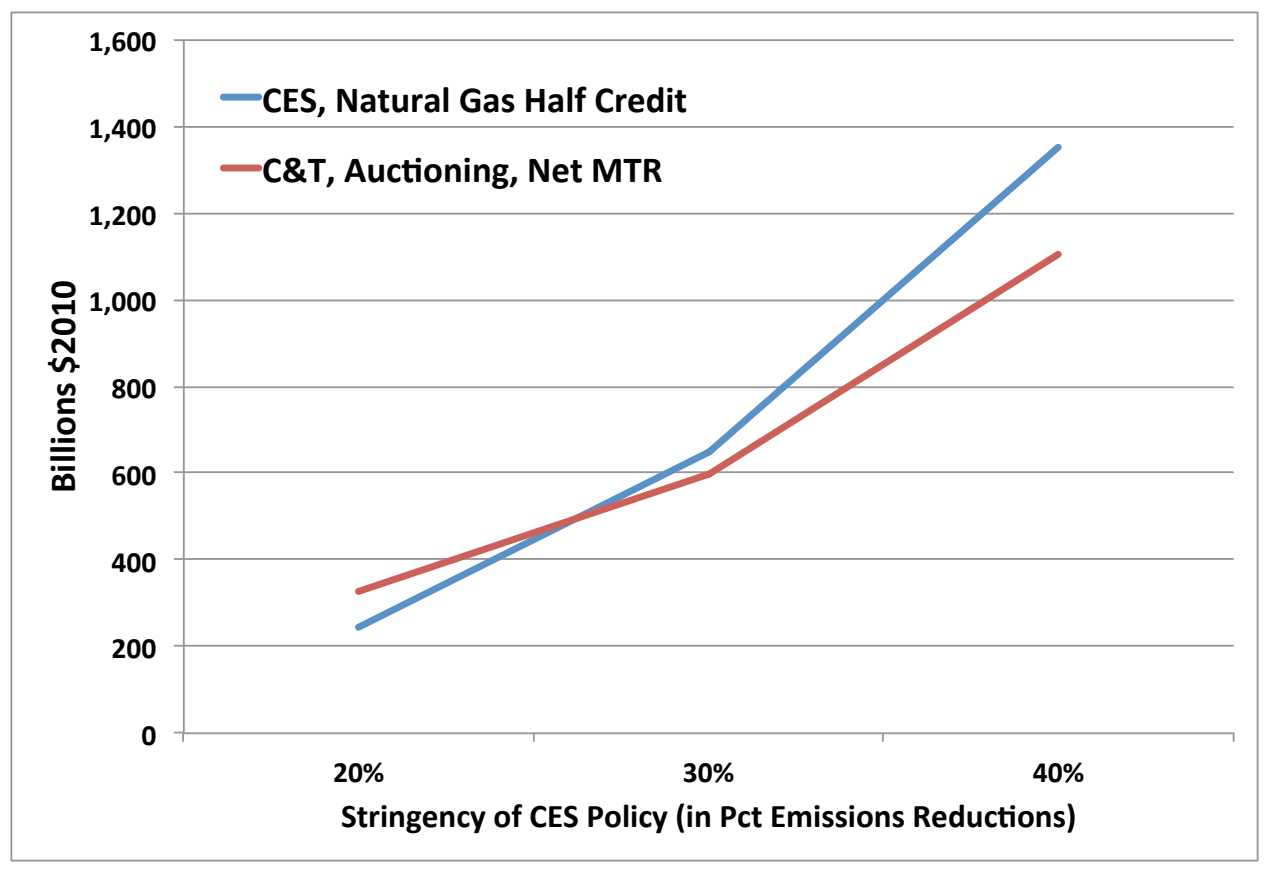


Figure 6. Percent Change in Demand for and Price of Retail Electricity

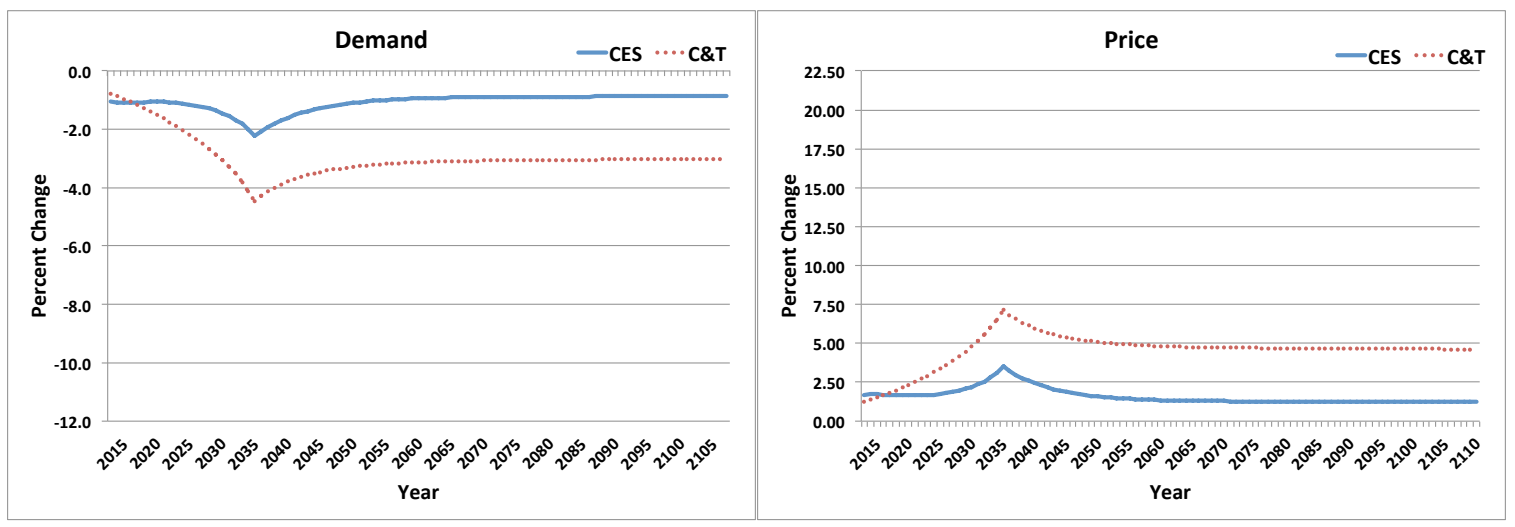

(a) $20 \%$ Long-Run Reductions

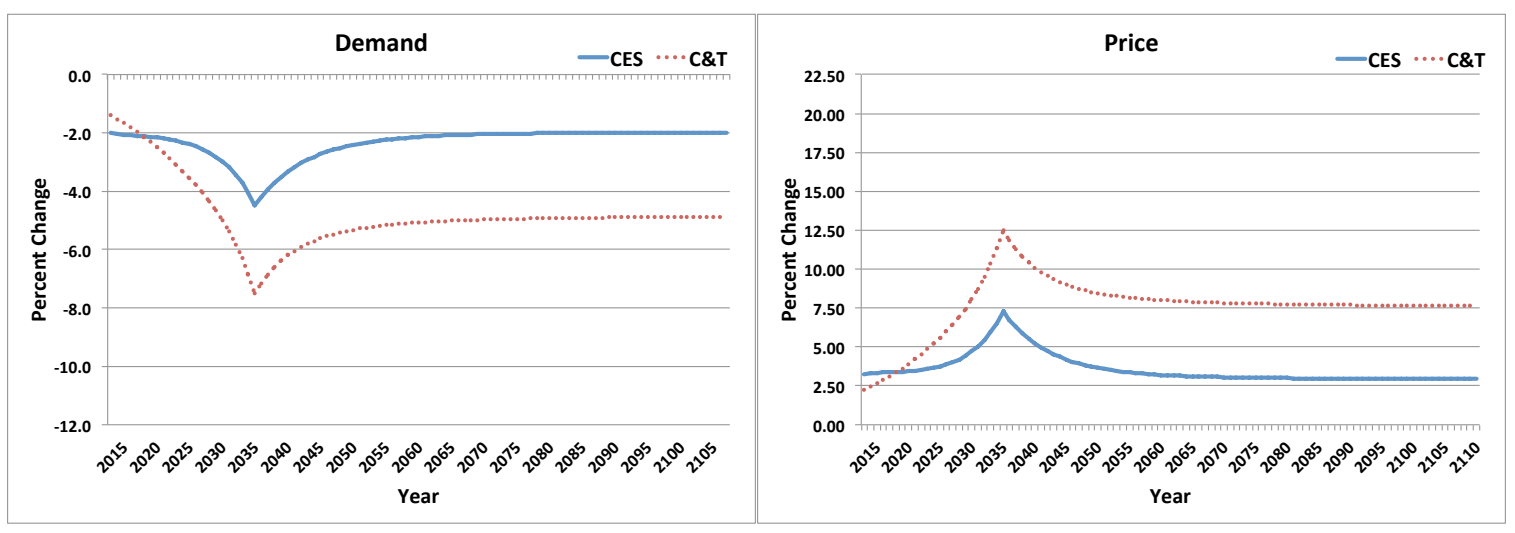

(b) $\mathbf{3 0 \%}$ Long-Run Reductions

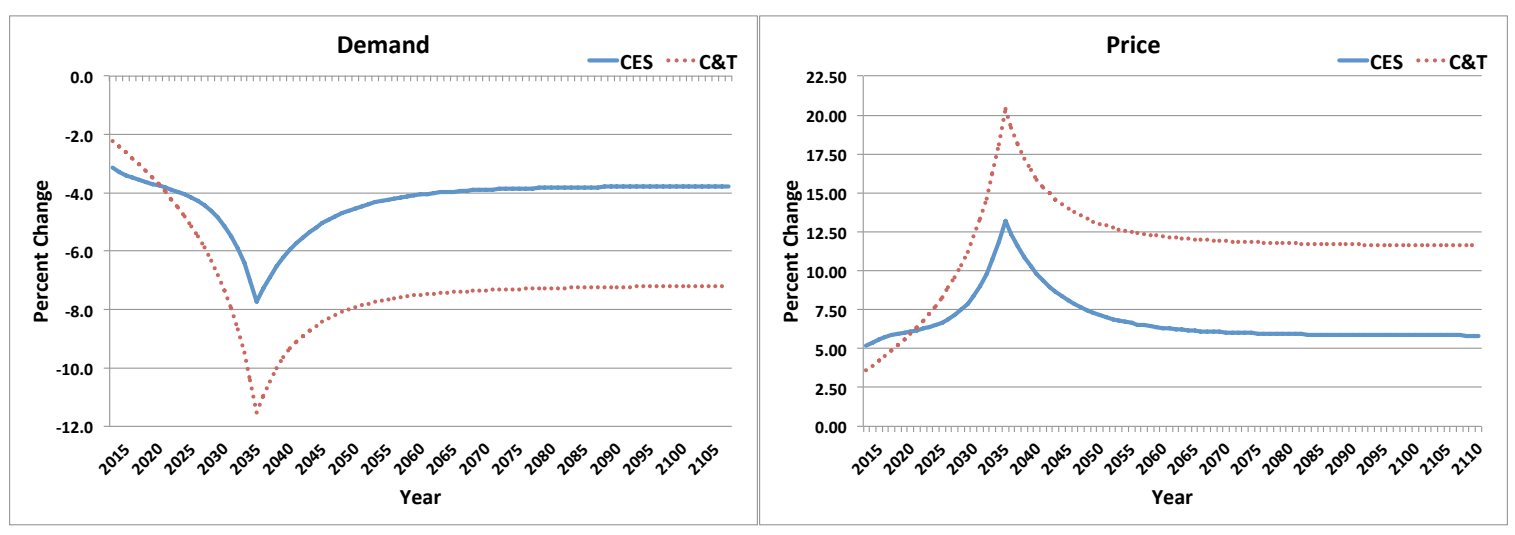

(c) $\mathbf{4 0 \%}$ Long-Run Reductions

45 
Figure 7. Percent Change in Price of Consumption Bundle

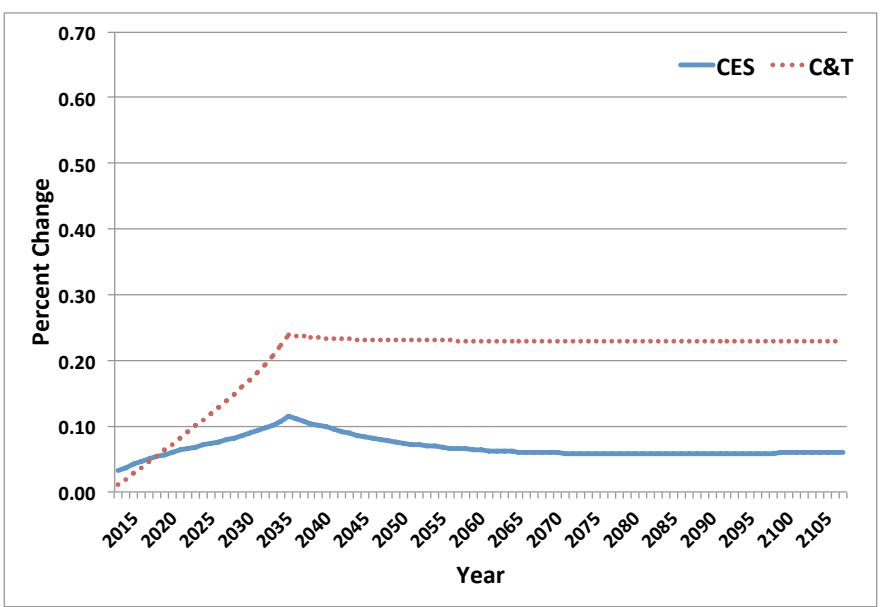

(a) $20 \%$ Long-Run Reductions

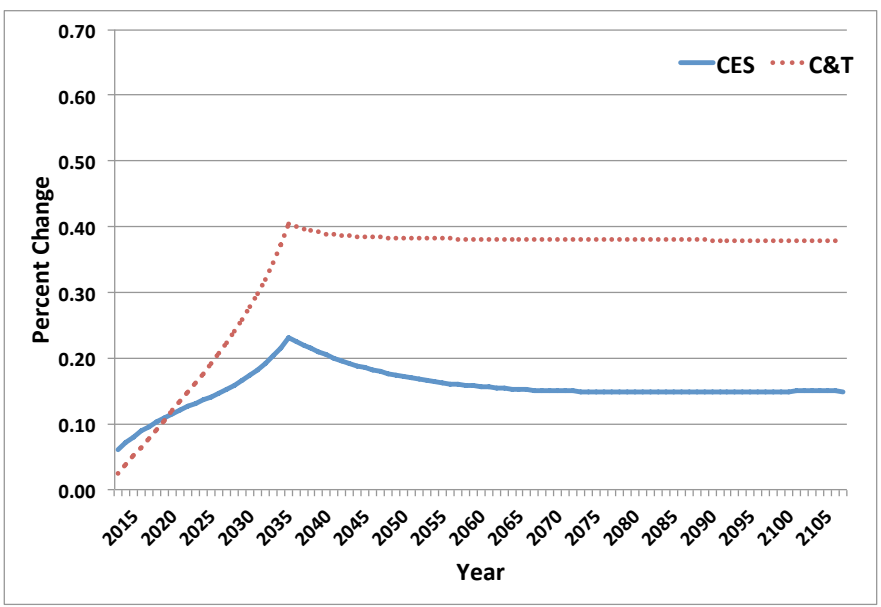

(b) $30 \%$ Long-Run Reductions

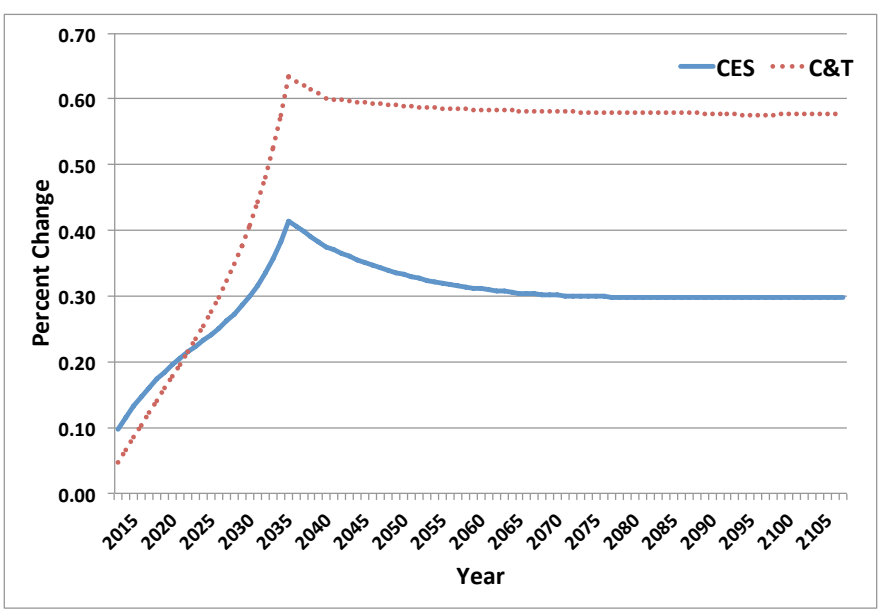

(c) $40 \%$ Long-Run Reductions 
Figure 8. Welfare Loss by Preexisting Tax Distortions

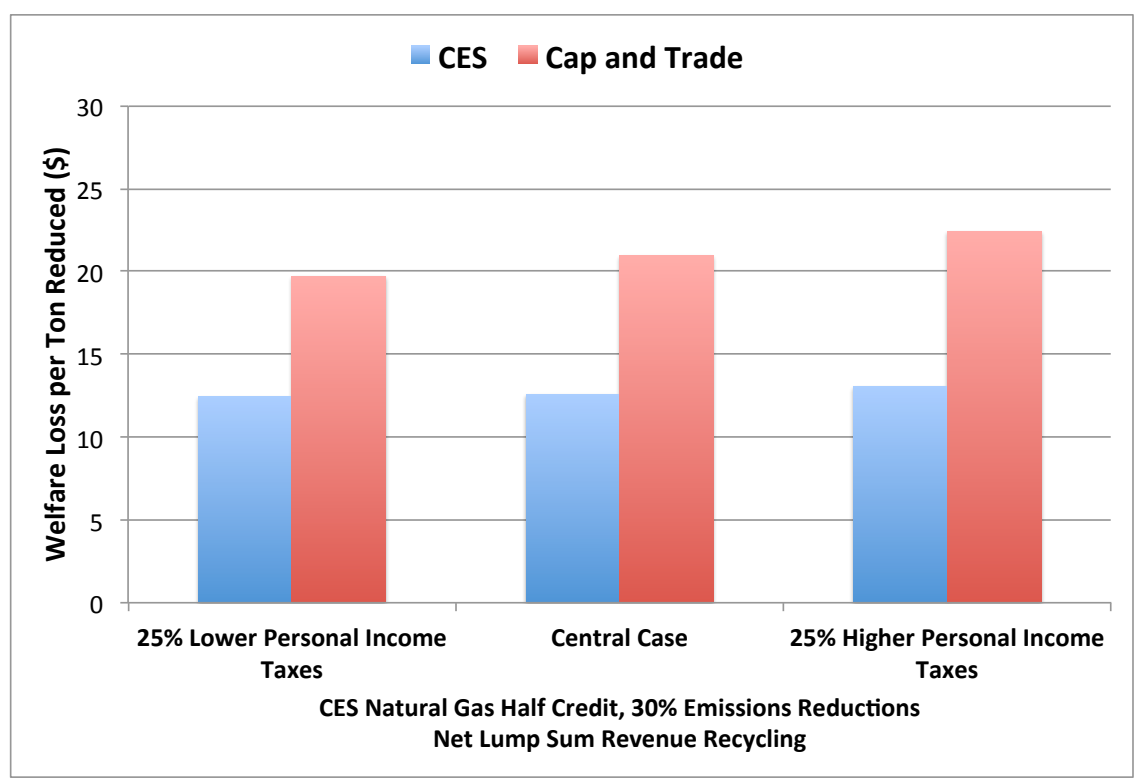

(a) Personal Income Taxes

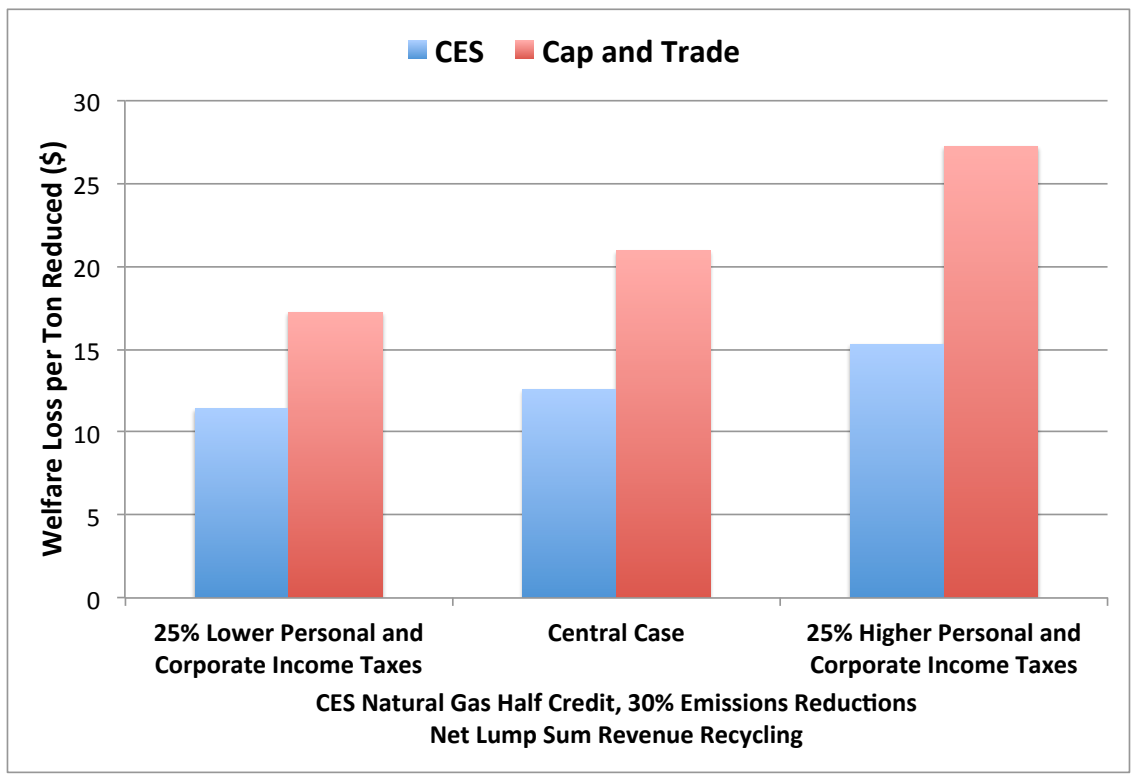

(b) Personal and Corporate Income Taxes 
Figure 9. Welfare Loss by Capital Intensity of Utilities

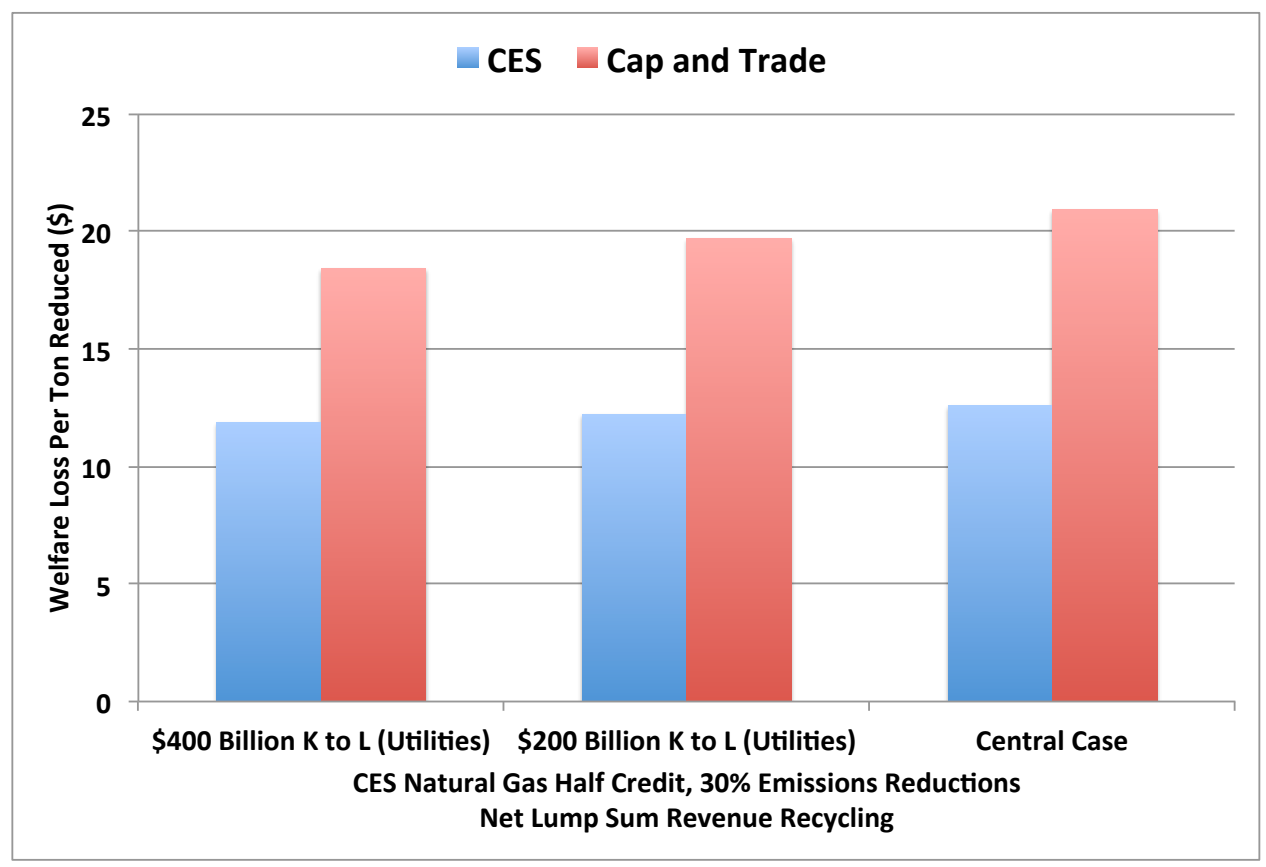

Figure 10. Welfare Cost by Revenue Recycling

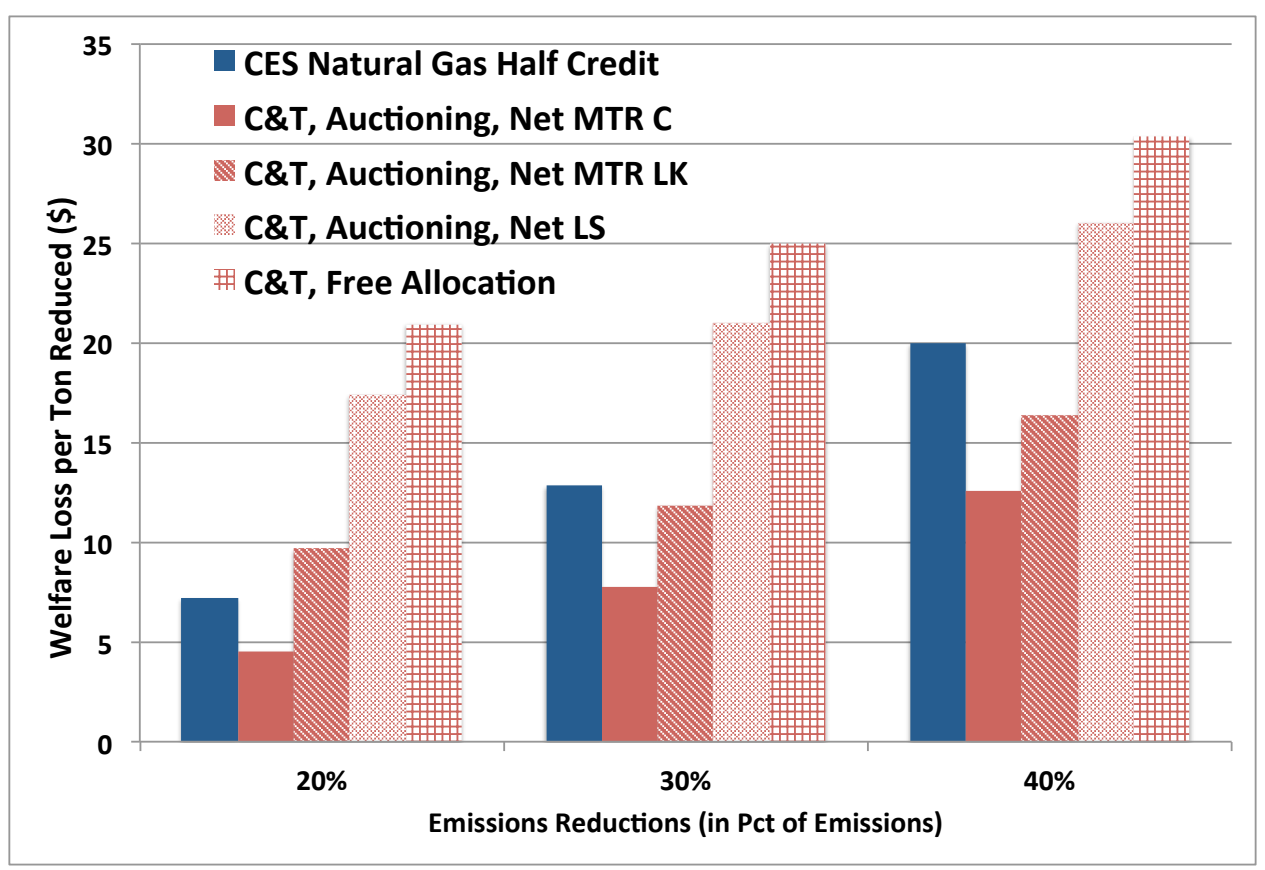


Figure 11. Relative Welfare Cost by Natural Gas Credit and Stringency

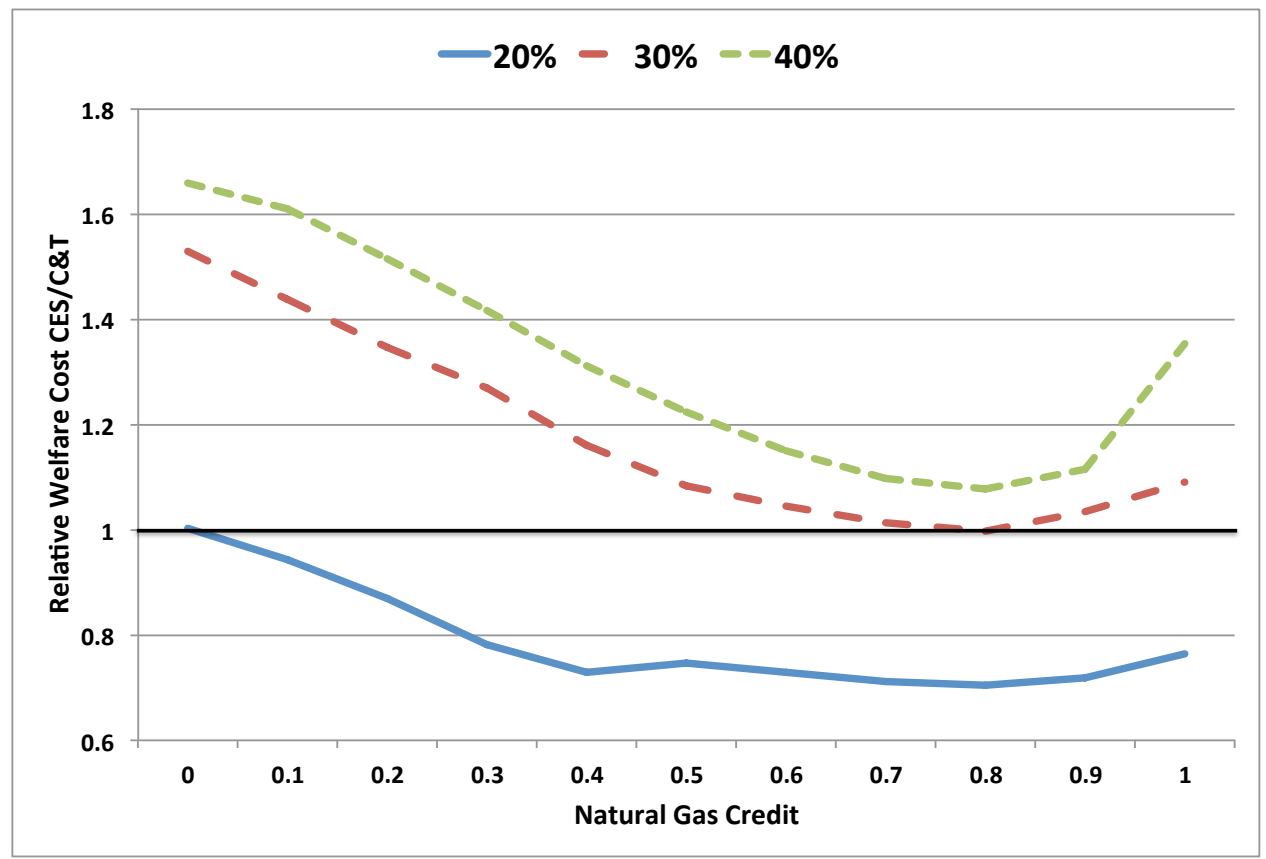

Figure 12. Welfare Costs by Elasticity of Labor Supply

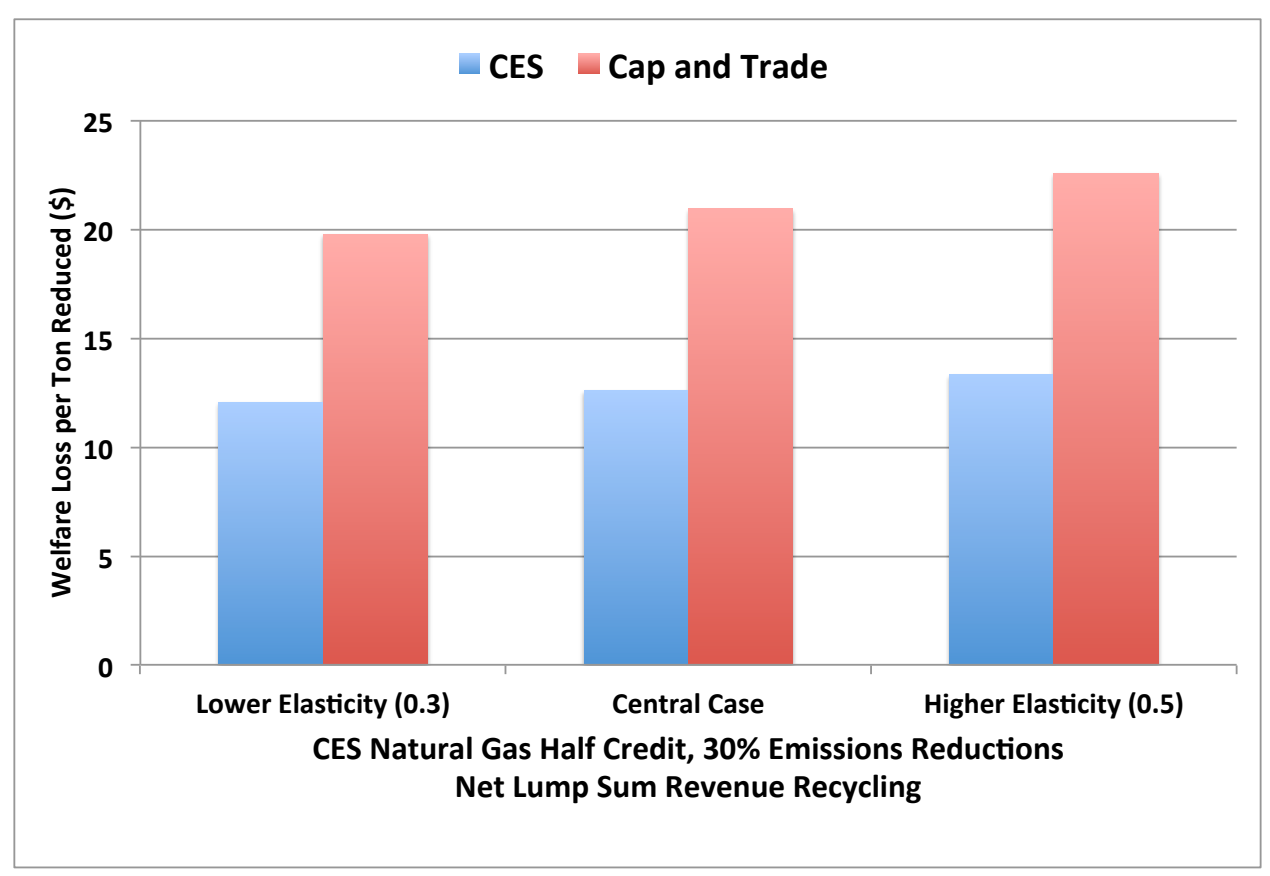


Figure 13. Welfare Costs by Elasticity of Substitution Between Generators

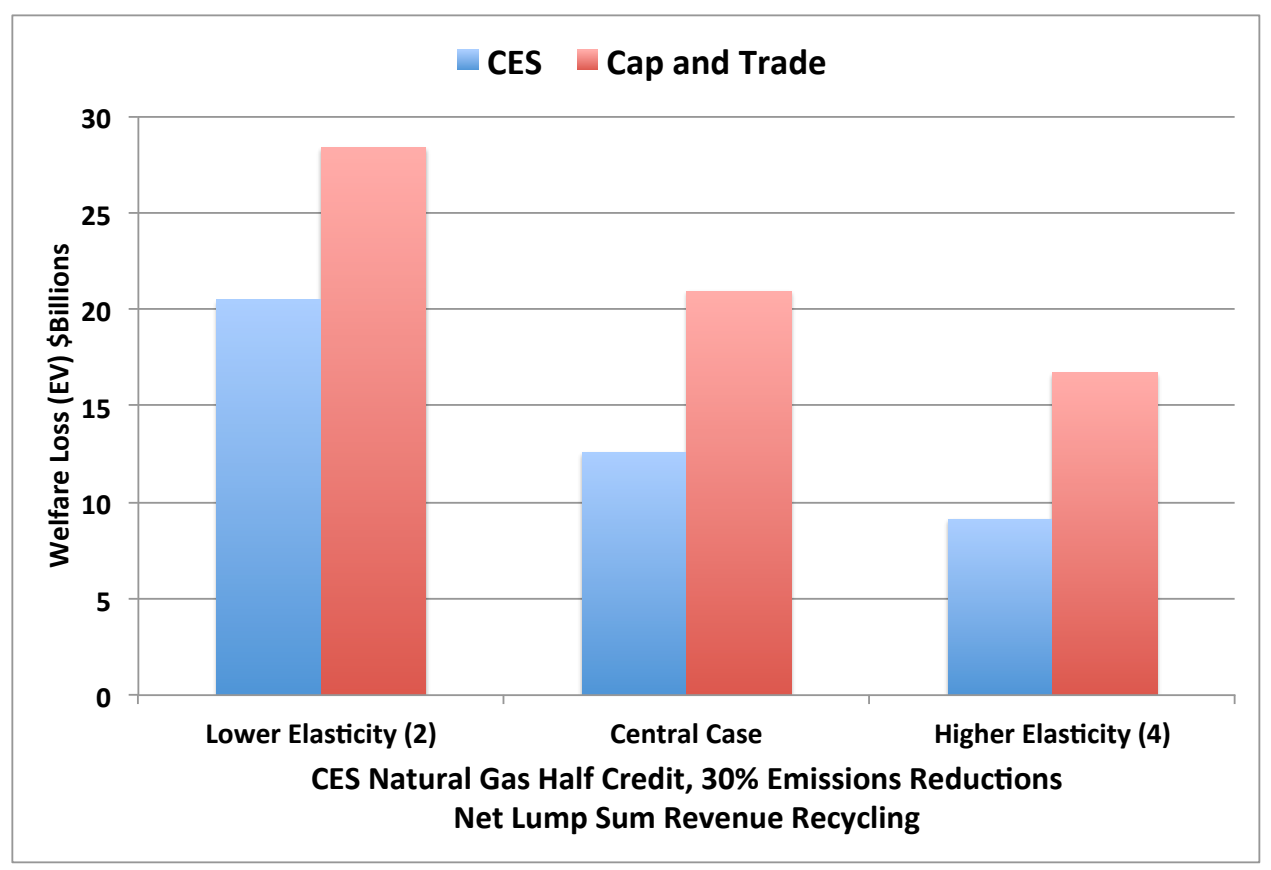

